\title{
Recent advances of PET imaging in clinical radiation oncology
}

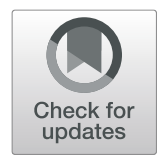

\author{
M. Unterrainer ${ }^{1,2,3^{*}}$, C. Eze ${ }^{4}$, H. Ilhan ${ }^{1}$, S. Marschner ${ }^{4}$, O. Roengvoraphoj ${ }^{4}$, N. S. Schmidt-Hegemann ${ }^{4}$, F. Walter ${ }^{4}$, \\ W. G. Kunz ${ }^{2}$, P. Munck af Rosenschöld ${ }^{5}$, R. Jeraj ${ }^{6}$, N. L. Albert ${ }^{1,3}$, A. L. Grosu7,8, M. Niyazi, ${ }^{3,4}$, P. Bartenstein ${ }^{1,3}$ and \\ C. Belka ${ }^{3,4}$
}

\begin{abstract}
Radiotherapy and radiation oncology play a key role in the clinical management of patients suffering from oncological diseases. In clinical routine, anatomic imaging such as contrast-enhanced CT and MRI are widely available and are usually used to improve the target volume delineation for subsequent radiotherapy. Moreover, these modalities are also used for treatment monitoring after radiotherapy. However, some diagnostic questions cannot be sufficiently addressed by the mere use standard morphological imaging. Therefore, positron emission tomography (PET) imaging gains increasing clinical significance in the management of oncological patients undergoing radiotherapy, as PET allows the visualization and quantification of tumoral features on a molecular level beyond the mere morphological extent shown by conventional imaging, such as tumor metabolism or receptor expression. The tumor metabolism or receptor expression information derived from PET can be used as tool for visualization of tumor extent, for assessing response during and after therapy, for prediction of patterns of failure and for definition of the volume in need of dose-escalation. This review focuses on recent and current advances of PET imaging within the field of clinical radiotherapy / radiation oncology in several oncological entities (neurooncology, head \& neck cancer, lung cancer, gastrointestinal tumors and prostate cancer) with particular emphasis on radiotherapy planning, response assessment after radiotherapy and prognostication.
\end{abstract}

Keywords: PET, Radiation oncology, Neuro-oncology, Head \& neck cancer, Lung cancer, Prostate cancer, Gl malignancies

\section{Introduction}

Radiotherapy plays a key role in the clinical management of patients suffering from oncological diseases, as approximately half of cancer patients directly benefit from individual radiotherapy during their disease course. In this disease course, radiotherapy can be applied as sole treatment or as a comprehensive treatment in combination with systemic treatments such as chemotherapy or

\footnotetext{
* Correspondence: marcus.unterrainer@med.uni-muenchen.de

'Department of Nuclear Medicine, University Hospital, LMU Munich, Marchioninistr. 15, 81377 Munich, Germany

${ }^{2}$ Department of Radiology, University Hospital, LMU Munich, Marchioninistr. 15, 81377 Munich, Germany

Full list of author information is available at the end of the article
}

local treatments such as surgery [1]. This high clinical significance for the treatment of oncological diseases is reached and maintained by the fast technological innovation and improvements that were introduced and subsequently established in clinical routine over the last decades [2], e.g. intensity-modulated radiation therapy (IMRT) has evolved as a widely used clinical treatment modality in many countries [3].

Anatomic imaging such as contrast-enhanced CT and MRI are widely available and are usually used to delineate the target volume for the subsequent radiotherapy. However, in the clinical routine in radiation oncology, diagnostic issues arise that cannot be sufficiently addressed by standard morphologic imaging. In particular,

C C The Author(s). 2020 Open Access This article is licensed under a Creative Commons Attribution 4.0 International License, which permits use, sharing, adaptation, distribution and reproduction in any medium or format, as long as you give appropriate credit to the original author(s) and the source, provide a link to the Creative Commons licence, and indicate if changes were made. The images or other third party material in this article are included in the article's Creative Commons licence, unless indicated otherwise in a credit line to the material. If material is not included in the article's Creative Commons licence and your intended use is not permitted by statutory regulation or exceeds the permitted use, you will need to obtain permission directly from the copyright holder. To view a copy of this licence, visit http://creativecommons.org/licenses/by/4.0/ The Creative Commons Public Domain Dedication waiver (http://creativecommons.org/publicdomain/zero/1.0/) applies to the data made available in this article, unless otherwise stated in a credit line to the data. 
the delineation of viable tumor tissue can be challenging, especially in patients with local pretreatment such as surgery. Moreover, treatment response assessment with conventional morphological imaging is partly unable to correctly differentiate early relapse from radiation induced changes or inflammation, e.g. in neuro-oncology [4]. Therefore, positron emission tomography (PET) imaging gains increasing clinical significance in the management of oncological patients undergoing radiotherapy, as PET allows the visualization and quantification of tumoral features on a molecular level beyond the mere morphological extent on conventional imaging, such as tumor metabolism or receptor expression. ${ }^{18} \mathrm{~F}$ FDG, a glucose analogue, is the most commonly applied ligand for oncological PET imaging [5] due to its proven utility and its generally increasing availability. Beyond the visualization of glucose metabolism, other tumor characteristics can be targeted and visualized by PET imaging. In this regard, e.g. PET with prostate-specific membrane antigen (PSMA) ligands are of high clinical and scientific interest for advanced imaging of patients suffering from prostate cancer [6]. The tumor metabolism or receptor expression information has allowed for use as a tool for (a) visualization of tumor extent, for (b) assessing response during and (c) after therapy, for (d) prediction of patterns of failure and for (e) definition of the volume in need of dose-escalation. Where, (e) sometimes has been referred to as "dose-painting" [7], although the idea is older [8] and the practice of escalation of the PET-avid volumes has been in long use for the treatment of e.g. head neck cancer.

This review describes the recent advances of PET imaging within the field of clinical radiotherapy / radiation oncology in several oncological diseases (neuro-oncology, head \& neck cancer, lung cancer, gastrointestinal tumors and prostate cancer) with particular emphasis on radiotherapy planning, but also on treatment response evaluation and prognostication. Moreover, recent advances in PET imaging itself are reviewed with special emphasis on the potential applicability on clinical settings in radiotherapy / radiation oncology.

\section{Neuro-oncology}

PET is widely applied in the field of neuro-oncology as complementary imaging modality in addition to MRI [9]. Its use may be derived from the answers to several key questions: 1) How to optimally define the radiotherapeutic target volume or delineate the extent of disease before surgical resection, 2) is it possible to derive prognostic value from molecular imaging, and 3) how to distinguish treatment effect from true progression.

When considering the wide field of primary CNS tumors, the entity of glioma is reported on by the PET task force of the Response Assessment in Neuro-Oncology
(RANO) working group [10]. This task force clearly derives evidence from published studies with validated PET findings (either by histopathology or clinical course) in the setting of diagnosis, biopsy, surgery, radiotherapy and response assessment, and shows superiority of amino acid PET such as ${ }^{18} \mathrm{~F}$-FET or ${ }^{11} \mathrm{C}$-MET PET [11] over ${ }^{18}$ F-FDG PET $[10,12]$. Specifically, ${ }^{18}$ F-FET has been shown to predict prognosis $[13,14]$, to enable improved target delineation [15-17] to assess treatment response [10]. Recurrence pattern analyses have substantiated the role of amino acid PET in identifying aggressive parts and the potential of targeting these regions $[18-21]$. In a recent study, the combination of ${ }^{18} \mathrm{~F}$ FET-PET and T1w MRI was shown to carry the most information for prediction of patterns of failure following chemo-radiation therapy of glioblastoma patients [22] In the US, ${ }^{18} \mathrm{~F}$-DOPA is a widely used tracer and it was shown to provide additional clinical information [23], which could also be validated histopathologically [24]. A variety of data exists on other tracers as described in Table 1 [28]. One potential target of interest for brain tumor imaging is the $18 \mathrm{kDa}$ translocator protein (TSPO), as known in neurodegenerative research, with remarkable overexpression in glioblastoma patients, whereas further studies have to further elucidate the contribution of neuro-inflammatory component within the signal obtained in TSPO PET [29-31]. In this regard, the potential influence of this new modality on radiotherapy approaches has to be validated. In sum, especially amino acid tracers are applied for radiotherapy planning in clinical routine of glioma patients $[9,15,20]$, but also for the differentiation of viable tumor and recurrent / progressive disease after initial radiotherapy [4, $32,33]$, as recently emphasized by the PET RANO group [10].

In analogy to primary brain tumors, brain metastases can also be visualized by PET [34]. Although its value for imaging prior to radiotherapy remains unclear, PET imaging, especially with radiolabeled amino acids, has evolved as complementary imaging tool for the differentiation of true progression from pseudoprogression, e.g. after radiotherapy [16, 35-37], see Fig. 1. Therefore, the use of PET in brain metastases was also recently recommended by the PET RANO group [34].

Compared to glioma and brain metastases, meningioma as extraaxial tumor is even more common. Beyond MRI, PET ligands targeting the somatostatin receptor (SSR) such as ${ }^{68} \mathrm{Ga}$-DOTATOC and ${ }^{68} \mathrm{Ga}$-DOTATATE are used in clinical routine $[38,39]$ and have been established for surgical guidance [40] or target volume definition $[41,42]$ due to the high expression of SSR in meningioma tissue. Specifically, this imaging modality is of help in meningiomas at the skull base, where extraforaminal extension or osseous infiltration may be expected 
Table 1 Different tumors and tracers in neuro-oncology for different indications: target delineation (TD), prognostication (P), distinguishing between progressive disease and pseudoprogression (TR)

\begin{tabular}{|c|c|c|c|}
\hline Tumor entity & Tracers & Indication & Comment \\
\hline \multirow[t]{4}{*}{ Glioma } & ${ }^{18} \mathrm{~F}-\mathrm{FET}$ & $\mathrm{TD} / \mathrm{P} / \mathrm{TR}$ & $\begin{array}{l}\text { Valuable as longer halftime compared to }{ }^{11} \mathrm{C}-\mathrm{MET} \text {, high diagnostic accuracy with histopathological } \\
\text { validation; ongoing trials to confirm clinical benefit, e. g. GLIAA [25] }\end{array}$ \\
\hline & ${ }^{18} \mathrm{~F}-\mathrm{DOPA}$ & $\mathrm{TD} / \mathrm{P} / \mathrm{TR}$ & $\begin{array}{l}\text { Studies on prognostic relevance and histopathological validation available, e.g. [24, 26], mainly used in the } \\
\text { US }\end{array}$ \\
\hline & ${ }^{11} \mathrm{C}-\mathrm{MET}$ & TD/P & Studies on prognostic relevance and histopathological validation available. Aiding in target delineation. \\
\hline & $\begin{array}{l}\text { TSPO } \\
\text { ligands }\end{array}$ & None & Investigational, no histopathological validation studies (ongoing) \\
\hline \multirow[t]{2}{*}{ Meningioma } & $\begin{array}{l}{ }^{68} \mathrm{Ga}- \\
\text { DOTATOC }\end{array}$ & TD & Aiding in target delineation or surgical approach, especially when located at the skull base \\
\hline & $\begin{array}{l}{ }^{68} \mathrm{Ga}- \\
\text { DOTATATE }\end{array}$ & TD & SUV cutoff histologically validated, no relevant data available on response \\
\hline $\begin{array}{l}\text { Brain } \\
\text { metastasis }\end{array}$ & ${ }^{18} \mathrm{~F}-\mathrm{FET}$ & TR & Differentiation pseudoprogression/radiation necrosis vs. tumor recurrence \\
\hline $\begin{array}{l}\text { CNS } \\
\text { lymphoma }\end{array}$ & ${ }^{18} \mathrm{~F}-\mathrm{FDG}$ & None & Tumor metabolism, response assessment [27] \\
\hline
\end{tabular}

[43] or in case of suspected residual or recurrent tissue after initial therapy [40]. Some other reports on amino acid PET are available as well, however, in the light of SSR-ligands, these tracers are not widely used in clinical routine for meningioma imaging [44]. Beyond in CNS lymphoma [45], ${ }^{18}$ F-FDG PET is not recommended by the PET RANO group for most primary brain tumors $[10,34,46]$, mainly due to high background activity of the normal brain.

\section{Head and neck cancer}

Head and neck cancers (HNC) consist of a wide range of tumor entities such as squamous cell cancer, salivary tumors or nasopharyngeal carcinomas. Diagnosis and treatment of the group of $\mathrm{HNC}$ is a complex and multidisciplinary approach. PET/CT provides insights into tumor biology and tissue metabolism and has an unprecedented accuracy in unmasking nodal metastases or tumor extensions. At the current state, most of the available data for PET imaging in HNC is validated for head and neck squamous cell cancer. PET/CT facilitates contouring for (chemo-) radiotherapy (CRT) and it significantly influences dose painting in radiation planning. In about $25 \%$ of patients with disease of unknown primary, location is revealed by ${ }^{18} \mathrm{~F}$-FDG-PET/CT [47-52].

Since HNC represents a very heterogeneous disease, there is great interest in finding prognostic markers for risk stratification. For primary staging, the use of PET/ CT leads to a change of about $10 \%$ in every TNM category and similarly, a major change in treatment strategy in about $10 \%$ of patients [53]. This is crucial, knowing that survival decreases by $40-50 \%$ in patients with

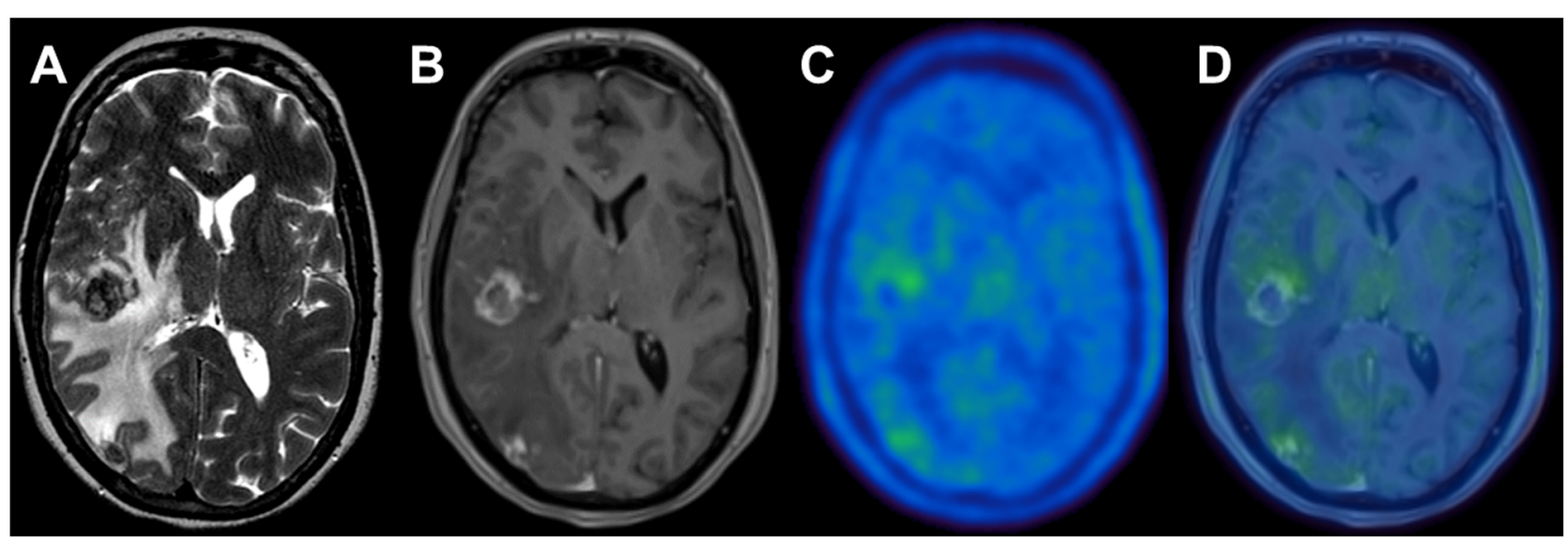

Fig. 1 A 54 years-old female patient with extensive edema on T2 MRI (a) and new contrast enhancing lesions at the temporal and occipital lobe (b) after undergoing stereotactic radiosurgery for brain metastases from malignant melanoma at both sites. MRI findings were suggestive for tumor recurrence, whereas only a faint uptake on ${ }^{18}$ F-FET PET (c) and fused PET/MRI (d) was seen in both lesions, a finding typical for radiation necrosis. Radiation necrosis was subsequently confirmed by histopathology 
positive lymph nodes $[48,49]$. Moreover, first data suggests that the use of $\mathrm{PET} / \mathrm{CT}$ for radiation planning could significantly improve the local tumor control, regional control and even survival [54]. The maximal standardized value $\left(\mathrm{SUV}_{\max }\right)$ of the primary tumor and total lesion glycolysis (TLG) of the largest node on ${ }^{18} \mathrm{~F}$-FDGPET are PET derived parameters that can be used as predictors of therapeutic failure and vice versa $[55,56]$. Due to the progress of artificial intelligence and deep learning, radiomics is increasingly becoming the focus of research [57, 58]. Here, radiomic texture parameters such as homogeneity and the sphericity described by Fujima et al. showed high association with the individual clinical course [57]. Moreover, e.g. low-intensity longrun emphasis (LILRE) performed before therapy was stated as a significant predictor of local control after CRT [59]. For a patient example please see Fig. 2.

Signatures similar to radiomics build derived from ${ }^{18} \mathrm{~F}$ FDG-PET and contrast-enhanced CT could even predict hypoxic areas of HNC [60], which is an important finding, as tumoral hypoxia is highly associated with an aggressive tumor phenotype that alters gene expression to promote survival in a hostile environment, which unfortunately causes a certain degree of therapeutic resistance [61]. Therefore, the identification of radiation-resistant tumor subvolumes may allow for intensified or hypoxiamodified treatment as well as stratification of patients [62]. Since the first application of hypoxia imaging with PET-ligands in 1981, various tracers like ${ }^{18}$ F-FETNIM, ${ }^{18} \mathrm{~F}$-HX 4 and ${ }^{18} \mathrm{~F}$-FMISO have been evaluated in cancer patients for detecting hypoxic hot spots [61]. Radiation dose escalation up to 77Gy to hypoxic areas detected by hypoxia-specific PET led to better local control without added toxicity, even, when hypoxia imaging used as imaging modality for response assessment during therapy, persistent tumoral hypoxia predicts poorer outcome [61, 63-67]. On the other hand, when comparing different tracers intra-individually, it could be shown that the detected hypoxic areas are often already covered by ${ }^{18} \mathrm{~F}$-FDG-avid areas or are in close proximity. Hence, hypoxic areas are mostly included, if radiotherapy is escalated to ${ }^{18}$ F-FDG-avid (sub-) volumes. However, this might lead to larger irradiated volumes and, as a consequence, potentially might result in a higher rate of side effects [68-70]. In sum, hypoxia imaging allows additional insights in molecular states of several tumor entities; however, the real clinical impact of this imaging modality remains to be elucidated further. Therefore, additional randomized controlled trials have to evaluate the effects of hypoxia imaging on the patient outcome.

Beyond imaging glucose consumption and hypoxia, PET ligands targeting the somatostatin receptor (SSR) such as ${ }^{68} \mathrm{Ga}$-DOTATATE can be used for imaging of undifferentiated nasopharyngeal cancer (NPC). Usually, SSR-ligands are used for imaging neuroendocrine tumors and meningioma [38, 71]. In NPC patients, SSR PET provides a high target-to-background contrast, which might be of particular help when infiltration at the skull base might be present [72-74]. In clinical routine of HNC patients, however, ${ }^{18}$ F-FDG-PET/CT plays the key role among these ligands.

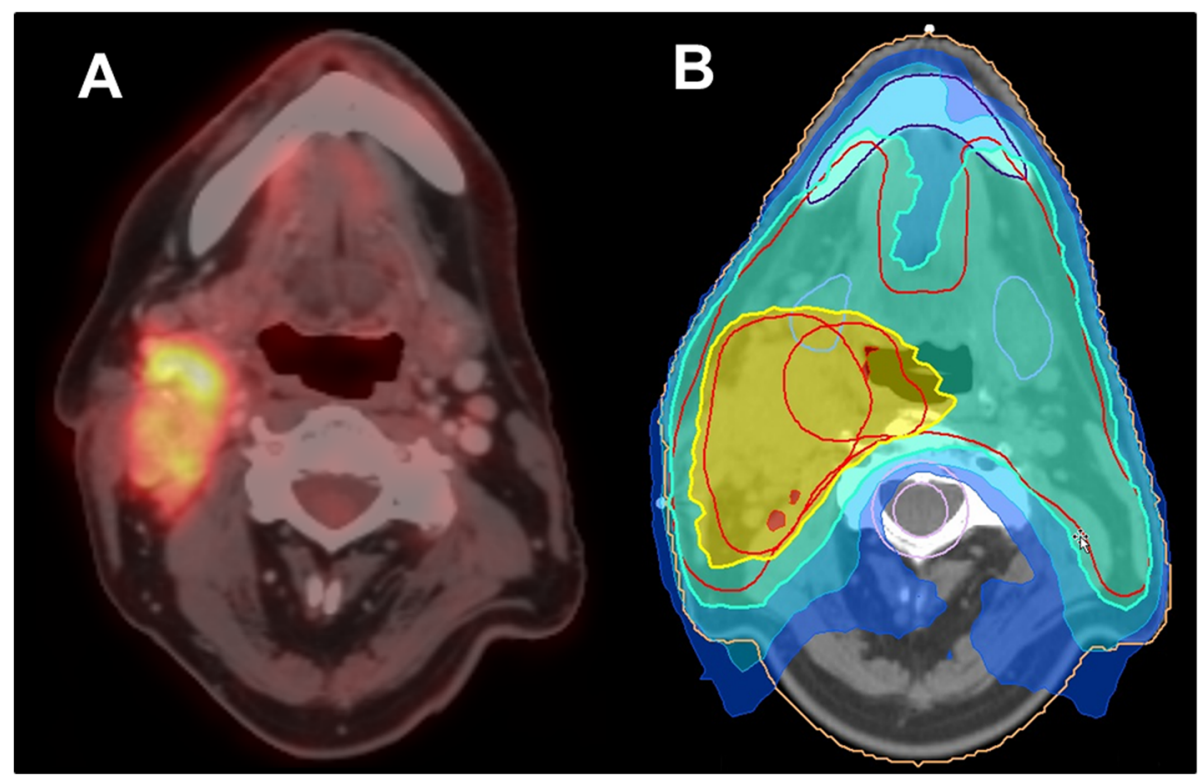

Fig. 2 Patient with HPV-positive squamous cell carcinoma of the right tonsil (T1 CN3 M0), who underwent ${ }^{18}$ F-FDG-PET/CT for staging prior to radiotherapy and subsequent inclusion of PET-positive tumor masses and lymph nodes in radiotherapy planning 
Comprehensive response assessment after initial therapy is important as salvage surgery or neck dissection might still be a curative option in these patients. Most problems occur while distinguishing between an incomplete response or inflammatory changes after CRT on conventional imaging. This could be improved by integrating the treatment plan into PET/CT imaging improving and the diagnostic accuracy for response assessment [75]. Moreover, several studies have evaluated the potential use of early treatment response assessment with PET/CT 4 weeks after CRT initiation [76]. In this setting, TLG of the primary tumor is described as prognostic factor for clinical outcome. The intra-therapy reduction of SUV$\max$ of the primary tumor was also associated with the locoregional control (LRC) and OS confirming this approach for early response assessment [77, 78]. Of note, PET/CT scans 1 week after CRT show no prognostic value, whereas, by contrast, $\mathrm{SUV}_{\max }$ of the primary tumor 12 weeks after finalizing therapy [79]. Unnecessary salvage neck dissections can be avoided by response assessment with PET/CT after 12 weeks for node assessment. This was partly validated with correlation to histological specimens [48, 80-82]. Detection of relapse is crucial in the post-treatment care. High false-negative values on conventional imaging can lead to delay the treatment of residual disease and therefore cause worsening in clinical outcome. Hence, ${ }^{18}$ F-FDG PET/CT with its high diagnostic accuracy is indispensable during follow-up [83]. The sensitivity and specificity for the detection of recurrences seems to be the highest between 4 and 6 months after therapy [84-86]. Altogether with the different tracers, high sensitivity and specificity, PET/CT is increasingly finding its way into clinical routine of staging, treatment planning and follow-up of head and neck cancer.

\section{Lung cancer}

Lung cancer remains the leading cause of cancer incidence and death worldwide, with 2.1 million new lung cancer cases and 1.8 million deaths predicted in 2018, corresponding to a fifth of cancer deaths. Non-small cell lung cancer (NSCLC) represents $80-90 \%$ of lung cancers, while small cell lung cancer (SCLC) shows a decreasing incidence in many countries over the past two decades [87, 88].

PET with ${ }^{18}$ F-FDG is widely used for staging patients with NSCLC $[89,90]$. In the PLUS trial, a large multicenter study, patients received either PET/CT staging or only conventional diagnostic CT. Here, the additional use of PET imaging to complete the staging prevented unnecessary surgery in a fifth of patients [91]. Beyond unnecessary surgery, superior mediastinal staging on PET vs. CT was confirmed in a large meta-analysis [92]. Overall, the combined information of hybrid imaging with PET/CT has been shown to have greater staging accuracy than both imaging modalities alone [93-97]. Recently, a number of studies have characterized the diagnostic value of PET/MRI demonstrating an equivalently high diagnostic performance in $\mathrm{T}$ and $\mathrm{N}$ staging of NSCLC [98-100]. For an example, see Fig. 3.

With regard to radiation treatment planning, ${ }^{18} \mathrm{~F}$-FDG $\mathrm{PET} / \mathrm{CT}$ has proven utility in accurate target volume delineation (TVD) [5]. On ${ }^{18} \mathrm{~F}$-FDG PET-CT, delineation of the metabolic tumor volume (MTV) with exclusion of abnormalities e.g. tumor-associated atelectasis or infiltrates improves inter- and intra-reader reproducibility $[101,102]$. Thus, combined PET/CT acquisition is the standard method of acquiring ${ }^{18} \mathrm{~F}$-FDG PET images for the purposes of baseline staging and for radiation treatment planning [103]. A large systematic review and meta-analysis confirmed that ${ }^{18} \mathrm{~F}$-FDG PET/CT for radiation treatment planning in lung cancer has a significant influence on the target definition. Approximately $40 \%$ of

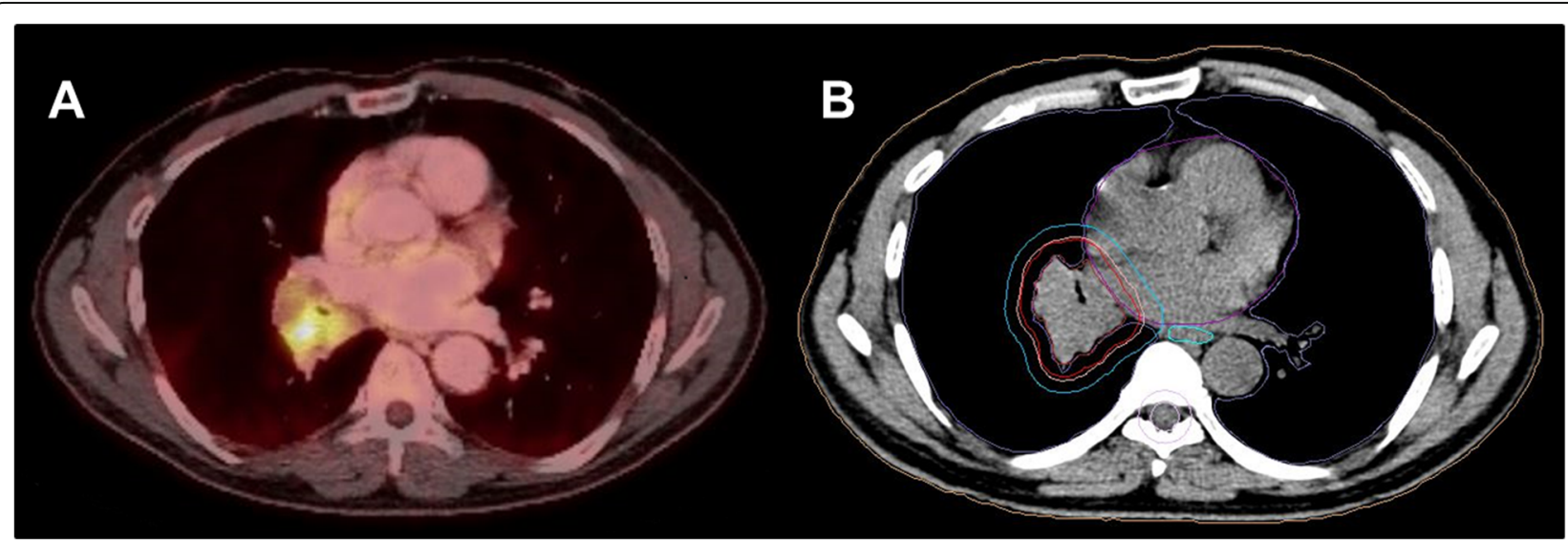

Fig. 3 A patient with newly diagnosed NSCLC (cT2b N3 M1b) and ${ }^{18}$ F-FDG PET/CT for staging (a) and inclusion in radiotherapy planning (b) 
patients had a significant change in target definition and $20 \%$ of patients were no longer eligible for curative intent (chemo)radiotherapy [104].

In 2015, the International Atomic Energy Agency (IAEA) provided a consensus report on PET/CT imaging for TVD in curative intent radiotherapy for NSCLC herein, extensive recommendations are provided for PET and CT image visualization and interpretation, tumor delineation and using planning CT with and without breathing motion compensation [105].

Furthermore, regarding assessment of treatment response, a secondary analysis of patients with pretreatment and post-induction PET/CT enrolled to the ESPATUE study - a phase 3 study of surgery vs. definitive concurrent CRT boost in patients with resectable stage IIIA[N2] and selected IIIB NSCLC after induction chemotherapy consisting of 3 cycles of cisplatin/paclitaxel and concurrent CRT (1.5 Gy twice-daily plus concurrent cisplatin/vinorelbine) was performed. The percentage of maximum standardized uptake value $\left(\% \mathrm{SUV}_{\max }\right)$ remaining in the primary tumor after induction chemotherapy (\% $\mathrm{SUV}_{\text {remaining) }}$ ) was predictive of survival and freedom from extracranial progression [106]. This parameter can be used for treatment stratification after induction chemotherapy or for evaluation of adjuvant novel systemic treatment options e.g. immunooncology (IO) therapies for high-risk patients. In the practice changing PACIFIC trial, which randomized stage III NSCLC patients to consolidation durvalumab vs. placebo every two weeks for up to 12 months following platinum-based concurrent CRT, data on inclusion of ${ }^{18} \mathrm{~F}$-FDG PET/CT in up-front staging and delivery of radiation therapy (pre- vs. post-treatment) is not available and would be of high interest [107, 108]. Currently a number of phase 2 studies are assessing the potential of PD-L1-directed PET imaging e.g. ${ }^{89} \mathrm{Zr}$-durvalumab or ${ }^{89} \mathrm{Zr}$-pembrolizumab to determine SUV of radiolabeled IO uptake in tumor lesions, correlate between tumor uptake and PD-L1 expression as determined by immunohistochemistry and potentially predict response rate (NCT03829007), (NCT03853187), (NCT02760225).

However, the role of PET/CT in SCLC remains uncertain, although international guidelines recommend its use [109]. Evidence has largely been based on small retrospective and non-randomized prospective studies, which have shown improvement in staging accuracy as well as providing additional prognostic information [110-113]. An unplanned post-hoc analysis of patients staged with additional ${ }^{18}$ F-FDG PET/CT (309/540 patients) in the CONVERT study - a multicenter phase 3 study, which randomized patients with limited stage SCLC to twice daily (45 Gy in 30 fractions or once-daily (66 Gy in 33 fractions) platinum-based CRT, survival outcomes (OS, PFS) were not significant. However, patients staged with ${ }^{18} \mathrm{~F}$-FDG PET/CT had smaller gross tumor volumes and received lower radiation doses to normal tissue (lung, heart, and esophagus). Caution should be taken, when interpreting these data as inherent confounders cannot be excluded. Importantly, the analysis does not address the role of ${ }^{18} \mathrm{~F}$-FDG PET/CT for TVD in particular [114].

Furthermore, there are some drawbacks vis-à-vis response assessment on PET e.g. acquisition time, PET parameters (SUV, total lesion glycolysis (TLG) and MTV) and cut-offs. The lack of an undisputed, univocal parameter remains a challenge. Nevertheless, a current systematic review addressed the role of interim ${ }^{18}$ F-FDG PET/ CT during.

CRT for early prediction of clinical outcome in NSCLC and showed that early identification of metabolic tumor response was a predictor of response and prognosis in NSCLC patients [115]. Kong et al. conducted a phase II trial in 42 inoperable stage II-III NSCLC patients, delivering individualized conformal CRT (39 pts./93\%) or RT alone (3 pts./7\%) to a fixed risk of radiation-induced lung toxicity (grade $>2$ ) and adaptively escalating the dose to the residual tumor defined on mid-treatment FDG-PET after an equivalent dose in 2 Gy per fraction (EQD2) of 50 Gy up to a physical total dose of $86 \mathrm{~Gy}$ (EQD2 of $92 \mathrm{~Gy}$ [alpha / beta $=10$ for tumor]) in 30 daily fractions and showed favorable LRC [116]. The RTOG 1106 trial is a follow-up ongoing clinical study from the same group validating this finding in a randomized manner (NCT01507428).

Moreover, residual metabolic tumor volume after definitive treatment could further determine prognosis: Ohri et al. reported that 30-month cumulative incidence rates of local progression were 32 and $5 \%$ for lesions with residual MTV $>25 \mathrm{~cm}^{3}$ vs. $<25 \mathrm{~cm}^{3}$, respectively [117]. Roengvoraphoj et al. demonstrated that pretreatment primary tumor (PT)-MTV $<63 \mathrm{~cm}^{3}$, posttreatment $\mathrm{PT}-\mathrm{MV}<25 \mathrm{~cm}^{3}$ and $\geq 15 \%$ reduction in midto post-PT-MV significantly improved OS [118]. In a follow-up analysis, the same group analyzed the prognostic value of a post-treatment PET/CT and demonstrated that PT-MTV reduction of at least $80 \%$ (complete and major metabolic response) improved patient outcome [119]. ${ }^{37}$

\section{Prostate cancer}

PET/CT PSMA-ligands labeled with ${ }^{68} \mathrm{Ga}$ or ${ }^{18} \mathrm{~F}$ is increasingly used in prostate cancer screening worldwide, as it provides an excellent target-to-background ratio leading to an improved detection rate [120]. PSMA is highly specific for prostatic tumoral tissue, even if PSMA expression in ganglia, sarcoidosis or benign bone diseases may lead to incidentally false-positive findings [121, 122]. A significant benefit in lymph node staging 
has been observed for PSMA PET/CT compared to standard of care imaging: A recent meta-analysis with histopathology as standard of reference and reported combined sensitivities and specificities of 80 and $97 \%$ at lesion level and 86 and $86 \%$ at patient level, either at initial staging and/or at biochemical recurrence [123-125]. However, PSMA PET/CT may still underestimate the true extent of nodal involvement, especially with regards to small lymph node metastases $<3 \mathrm{~mm}[126,127]$. Hence, PSMA PET/CT at the current state may probably not yet allow a perfect node-based therapeutic approach alone, e.g. stereotactic body radiotherapy (SBRT) in comparison to elective nodal radiotherapy (ENRT) [128] or limited salvage lymph node dissection (SLND) compared to super-extended SLND [129]. For detection of bone metastases, PSMA PET/CT outperformed planar bone scans in two large analyses [130, 131]. Only few institutions have the possibility to perform PSMA PET/ MRI and head to head comparisons between PSMA PET/MRIs and PET/CT are scarce. Overall, there seems to be a very low discordance between the two imaging techniques including PET-positive lymph nodes of normal size [132].

One further unique characteristic of PSMA PET/CT is its high detection rate of metastases even at low prePET PSA levels, e.g. at PSA level $<0.2 \mathrm{ng} / \mathrm{ml}$ in $33 \%$ and at $0.2-0.49 \mathrm{ng} / \mathrm{ml}$ in $45 \%$ of the patients, which partly explains the high impact of PSMA PET/CT on the individual patient management, particularly, in patients with biochemical recurrence or persistence [123, 133, 134]. So far, high-level evidence on the benefit of an earlier detection of node or distant metastases is missing and randomized controlled trials evaluating the management and outcome of patients with PSMA PET-positive disease are currently under way. Thus, up to now there are no clear recommendations in the European or NCCN guidelines on application of PSMA PET/CT at initial staging and only a weak recommendation for patients with persistent or recurrent PSA [135]. Nevertheless, particularly in the postoperative setting in persistent or recurrent disease prior to radiotherapy, evidence is accumulating: recently, a single-arm prospective trial on 635 patients with biochemically recurrent prostate cancer reported a high detection rate of $75 \%$ and a substantial inter-reader reproducibility for PSMA PET/CT [136]. From a prospective survey, it is known that information from PSMA PET/CT lead to management changes in more than $50 \%$ of prostate cancer patients with biochemical recurrence [137]. With special regard to radiotherapy, the specific impact of PSMA PET/CT on salvage radiotherapy was investigated in patients with a PSA recurrence of $<1.0 \mathrm{ng} / \mathrm{ml}$ after radical prostatectomy: In this analysis, patients had a median PSA of $0.48 \mathrm{ng} / \mathrm{ml}$ and the PSMA PET/CT result was compared to standard of care Radiation Therapy Oncology Group (RTOG) clinical target volume (CTV) of both the prostate bed and the pelvic lymph nodes. Overall, 132 of 270 included patients had PSMA PET-positive lesions and 52 patients had at least one lesion not covered by consensus CTVs [138]. These findings have led to a randomized imaging trial of salvage radiotherapy with or without PSMA PET/CT (NCT03582774) investigating its potential benefit on clinical outcome in a prospective setting [139]. So far, few retrospective studies reported patient outcome after PSMA PET/CT-based salvage radiotherapy. The mean PSA response rate in these studies was $74 \%$ (range, $60-83 \%$ ) after a mean follow-up time of 19 months [140-144], for an example see Fig. 4. Overall, one might expect that PSMA PET/CT improves salvage radiotherapy and thereby potentially outcome in numerous ways: Firstly, visualizing macroscopic recurrence allows for dose-escalation. Secondly, CTVs can be expanded to areas not normally treated by consensus CTV. Thirdly, macroscopic recurrence might lead to

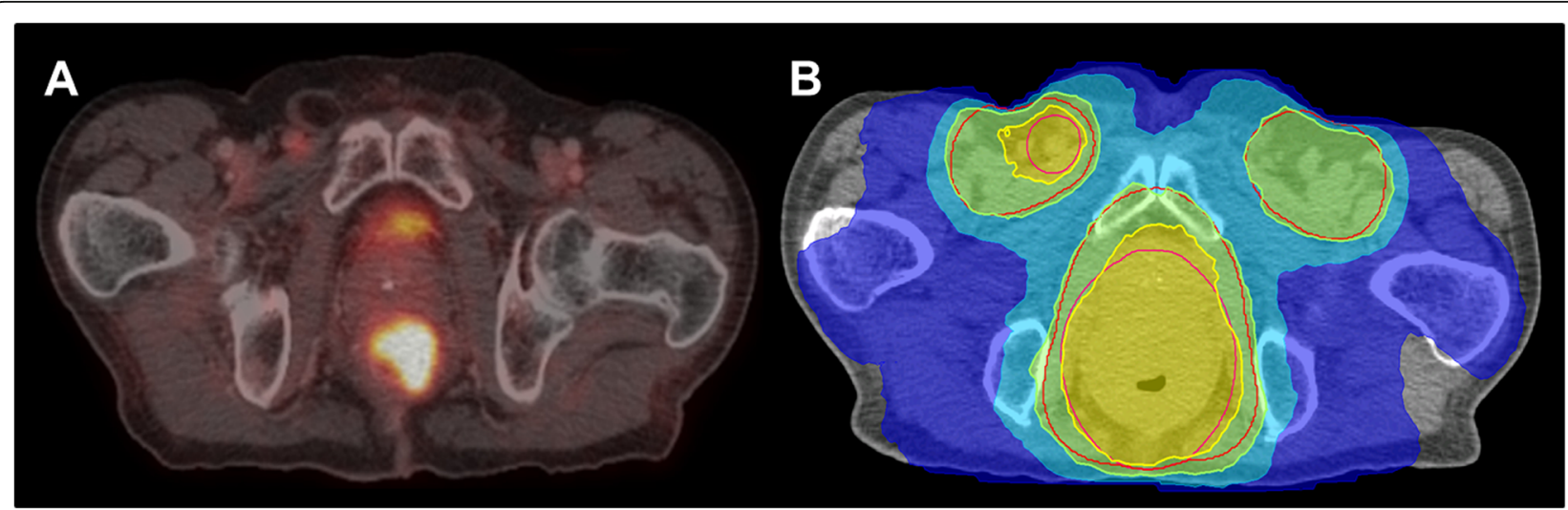

Fig. 4 A 68-years old male patient with newly diagnosed anal cancer Stage IIIC (CT4 CN1 CM0) and ${ }^{18} \mathrm{~F}-\mathrm{FDG}$ PET/CT with ${ }^{18} \mathrm{~F}-\mathrm{FDG}$ avid primary tumor and inguinal lymph node (a). ${ }^{18} \mathrm{~F}-\mathrm{FDG}$ PET/CT was then used for radiotherapy planning with boost to the right inguinal lymph nodes and primary tumor (b) 
early application of androgen deprivation therapy concurrent with radiotherapy and finally, salvage radiotherapy might be abandoned in case of overt metastatic disease. Regarding primary prostate cancer, current research is focusing on the identification and accurate contouring of the intraprostatic tumor volume based on PSMA PET/CT in order to allow for focal radiation therapy with dose escalation to the PSMA PET-positive lesions within the prostatic gland $[145,146]$. For intraprostatic boosting, PSMA PET/CT may even replace multiparametric MRI (mpMRI): In a prospective validation study, an increased consensus of PSMA PET/CT with histopathologic correlation was observed for intraprostatic gross tumor volume delineation compared to mpMRI. Additionally, mpMRI contours significantly underestimated tumor volume [147]. Also, analysis of radiomic features gain access into the evaluation of prostate cancer patents [148]. In recent years, treatment of oligometastatic prostate cancer has sparked new interest since the STAMPEDE trial reported a significant overall survival benefit by prostate radiotherapy and life-long ADT in patients with low metastatic burden [149] and the STOMP trial an ADT-free longer survival by metastasis-directed therapy vs. surveillance [150]. This has led to various studies all incorporating PSMA PET/ $\mathrm{CT}$ as diagnostic imaging like the PEACE $\mathrm{V}$ trial (NCT03569241) or the "Prostate Cancer Subclinical Metastatic Ablative MR-guided Radiotherapy" study (NCT03160794).

Moreover, in analogy to neuroendocrine tumors, where radioligands labeled with the beta-emitters such as ${ }^{177} \mathrm{Lu}$-DOTATATE are approved and successfully used in clinical routine [151], PSMA-ligands labeled with

${ }^{177} \mathrm{Lu}$ can also be used for radioligand therapy [152]. In several countries, PSMA-ligands show to be a valuable treatment option in patients with metastasized, castration-resistant prostate cancer, so that several trials such as the "VISION" trial (NCT03511664) are on their way.

Overall, the use of PSMA PET/CT prior to radiotherapy of primary or postoperative prostate cancer warrants further high-level research to find its rightful place in the current guidelines. Nevertheless, the available evidence already suggests that PSMA PET/CT will become an even more decisive tool in the guidance and treatment of prostate cancer patients than it nowadays already is.

\section{Gastrointestinal oncology}

Radiation oncology is a crucial part of the treatment in several gastrointestinal tumors. Particularly in curative intended treatment of esophageal carcinoma, rectal cancer, and anal cancer radiotherapy (RT) is a key treatment modality. The impact of ${ }^{18} \mathrm{~F}$-FDG PET/CT on staging of patients with gastrointestinal malignancies, radiation treatment planning, and response assessment is well established.

\section{Esophageal cancer}

In curative treatment of patients with locally advanced esophageal cancer chemoradiation (CRT) is either performed as neoadjuvant treatment before surgery or as definitive treatment in case of unresectable tumor. Neoadjuvant treatment is performed in patients who are fit to undergo major surgery. However, patients with thoracic squamous cell carcinoma of the esophagus who show good response to CRT might have a similar outcome with definitive CRT compared to surgery [153]. Several studies have gathered evidence that ${ }^{18}$ F-FDG $\mathrm{PET} / \mathrm{CT}$ has a high prognostic value in patients undergoing CRT for esophageal cancer [154, 155] and can therefore be useful to guide treatment decisions.

RT planning in patients with esophageal cancer is challenging since the primary tumor is often poorly visible on standard morphological imaging with $\mathrm{CT}$ alone. Given the submucosal spread of the tumor, diagnostic modalities such as barium swallow, gastroesophagoscopy or MRI are frequently used to further determine the exact tumor extend. While the additional effect of ${ }^{18} \mathrm{~F}$ FDG PET/CT on primary tumor volume delineation seems limited with different studies reporting conflicting results either with benefit [156] or no benefit [157] of $\mathrm{PET} / \mathrm{CT}$ over conventional imaging alone. In contrast, the effect on metabolic imaging on the identification of involved nodes has been shown [157, 158]. ${ }^{18}$ F-FDG PET/CT has a high specificity and sensitivity in detecting involved nodes in esophageal cancer and should therefore be considered for pre-treatment imaging in patients with esophageal cancer [159].

\section{Pancreatic cancer}

RCT or stereotactic radiotherapy [160] can be offered to patients as part of multidisciplinary treatment in locally advanced pancreatic cancer (LAPC) either as neoadjuvant or as definitive treatment. The pancreas is localized in close proximity to highly radiation sensitive organs such as the duodenum and small bowel that need to be spared [161]. Large safety margins to account for internal movement and positioning uncertainties are therefore obsolete and precise tumor delineation remains the main challenge in treatment planning of LAPC. While malignancies of the pancreas can be imaged using different PET tracer such as ${ }^{18} \mathrm{~F}-\mathrm{FDG}$ and ${ }^{18} \mathrm{~F}$-fluorothymidine (FLT) [162] the value of metabolic imaging for delineating GTV in pancreatic cancer remains debatable. Due to a long acquisition phase encompassing several breathing cycles misregistration 
between PET and CT occur and can lead to uncertainties in determining the actual tumor extend [163].

Concerning patient management pre-therapeutic ${ }^{18} \mathrm{~F}$ FDG PET/CT has a prognostic value as initial low SUVmax showed an association with better median survival after SBRT in one study with 55 LAPC patients [164]. Accordingly another study with 33 patients reported that high metabolic tumor volume (MTV) and total lesion glycolysis (TLG) prior to induction gemcitabine and SBRT were associated with inferior overall survival [165]. A histopathological correlation in patients with borderline resectable pancreatic carcinoma and LAPC undergoing multimodality neoadjuvant treatment showed both post-neoadjuvant CA19-9 and postneoadjuvant therapy $\mathrm{SUV}_{\max }$ significantly correlating with tumor regression grade [166].

\section{Rectal cancer}

Neoadjuvant RT or CRT before total mesorectal excision (TME) is well established in the treatment of locally advanced rectal cancer (LARC). It has been proven that pathological complete response (pCR) after CRT correlates with improved long-term outcome [167]. Moreover, a correlation between applied radiation dose and pCR was found $[168,169]$. Therefore, to further improve response to neoadjuvant treatment while sparing normal tissue focal dose escalation on macroscopic tumor seems worthwhile [170]. Commonly, CT-based radiation treatment planning is complemented by MRI information for better soft tissue contrast. In a prospective study, gross tumor volume delineation on MRI and ${ }^{18} \mathrm{~F}$-FDG PET/ CT was compared in 77 patients [171]. The authors concluded that ${ }^{18} \mathrm{~F}$-FDG PET/CT added important information for the delineation process with PET-based GTV been smaller than MRI-based GTV but larger GTV volumes when both MRI and PET information was used. A comparison of tumor extend in pathological specimens even showed a better correlation to tumor extend measured on ${ }^{18} \mathrm{~F}$-FDG PET/CT than on CT or MRI [172] underlining the importance of including metabolic imaging in the initial treatment planning.

In up to $20 \%$ of patients with LARC pCR can be achieved after neoadjuvant CRT [173]. This high rate of pathological response fuels efforts to provide organpreserving treatment to patients with good clinical response [174] thus emphasizing the need for valid treatment assessment. So far, post-treatment ${ }^{18}$ F-FDG PET/ CT has been evaluated extensively in retrospective studies with promising results [175-178]. However, at this stage, further validation is needed.

\section{Anal cancer}

Squamous cell carcinoma of the anus (SCCA) is a rare disease accounting for approximately $1-2 \%$ of gastrointestinal tumors only [179]. CRT is the treatment of choice for curative intended organ-preserving treatment with surgery reserved for salvage. The majority of SCCA is highly ${ }^{18} \mathrm{~F}$-FDG-avid [180] and multiple studies have described a change in tumor staging in up to $20 \%$ of cases with the use of ${ }^{18} \mathrm{~F}$-FDG PET/CT $[181,182]$.

Concerning radiation treatment planning metabolic imaging can be useful to guide target definition of elective lymph nodes regions and boost to primary tumor, see Fig. 5. A recent meta-analysis reported a change in target volume delineation with the use of ${ }^{18} \mathrm{~F}$-FDG PET/ CT in almost $25 \%$ of patients [183] compared to treatment planning based on conventional imaging. More specifically, ${ }^{18}$ F-FDG PET/CT contributes to identifying involved lymph nodes that need to be included into the radiation field. A recent study evaluated the distribution of involved lymph nodes on PET/CT and correlated their findings with three established delineation guidelines. The authors reported detection of involved lymph nodes outside the borders of standardized clinical target

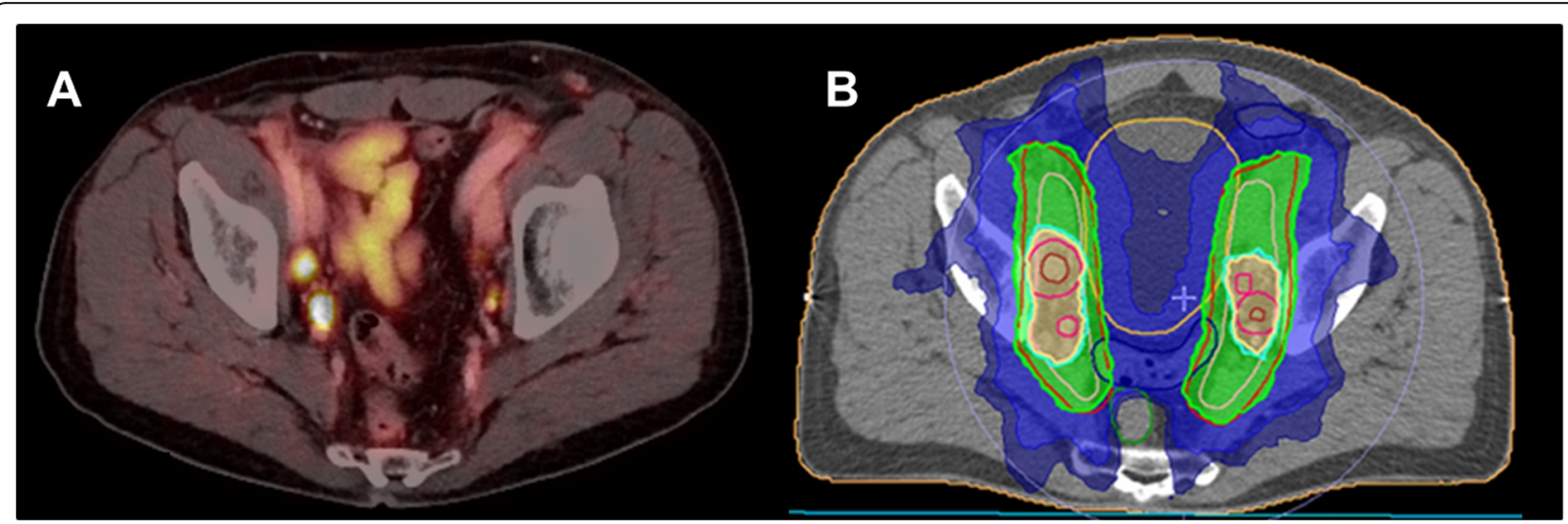

Fig. 5 A 69-years old patient with biochemical recurrence of prostate cancer (pT2c pNO R0 Gleason score 9, preoperative PSA $11.7 \mathrm{ng} / \mathrm{ml}$ ) and evidence of PET-positive lymph node metastases (a) and radiotherapy-plan with dose-escalation to the PET-positive lymph nodes (b) 
volumes (CTV) recommended by the respective delineation guidelines of $10-29 \%$ [184]. The impact on ${ }^{18} \mathrm{~F}$ FDG PET/CT on delineation of primary tumor gross tumor volume (GTV) has been described by Krengli et al. They reported that metabolic imaging had a greater influence on GTV definition than on CTV delineation [185]. Attempts to identify ${ }^{18}$ F-FDG-avid subvolumes for further dose escalations within the primary tumor have been made [186] however, this approach needs further research. Utilization of metabolic imaging as biomarker for the prediction of treatment outcome in anal cancer has been evaluated intensively. Several retrospective and prospective studies have reported on the value of ${ }^{18} \mathrm{~F}$-FDG PET and PET/CT for early detection of tumor recurrence as well as the predictive value of different parameters in pre- and posttreatment ${ }^{18} \mathrm{~F}$-FDG PET/CT for response assessment [187-190] with promising results.

\section{Summary}

PET imaging is increasingly used in the clinical management of patients undergoing radiotherapy. Especially, this is the case for a broad variety of cancer entities, as presented in the current manuscript. Moreover, PET imaging is increasingly included in randomized trials focused on radiotherapy, where parameters from PET are used as imaging biomarkers. Hence, in radiation oncology practice, imaging biomarkers derived from PET comprise valuable additional information beyond standard morphologic imaging for tumor staging, radiotherapy planning, but also - after undergoing radiotherapy for treatment monitoring and the differentiation of tumor relapse from inflammatory or radiation induced changes. So far, ${ }^{18}$ F-FDG is the most widely used tracer as described above; however, there is a strong trend towards radioligands, which target more specific tumor features rather than only glucose metabolism, e.g. PSMA-targeted ligands for prostate cancer imaging or SSR-directed ligands for meningioma imaging. Along with anticipated technical innovations such as whole body PET, methodological innovations such as the application of PET-derived radiomics and deep learning methods will further improve tumor characterization, identification and, hence, the clinical workup of patients undergoing radiotherapy.

\section{Acknowledgements}

None.

\section{Authors' contributions}

MU: conception, manuscript draft, literature review, increased intellectual content, revision. CE: manuscript draft, literature review, increased intellectual content, revision. HI: literature review, increased intellectual content, revision. SM: manuscript draft, literature review, increased intellectual content, revision. OR: manuscript draft, literature review, increased intellectual content, revision. NSH: manuscript draft, literature review, increased intellectual content, revision. FW: manuscript draft, literature review, increased intellectual content, revision. WGK: conception, increased intellectual content, revision. PMR: conception, increased intellectual content, revision. RJ: conception, increased intellectual content, revision. ALG: conception, increased intellectual content, revision. NLA: conception, increased intellectual content, revision. MN: manuscript draft, literature review, increased intellectual content, revision. PB: conception, increased intellectual content, revision. CB: conception, manuscript draft, literature review, increased intellectual content, revision. The author(s) read and approved the final manuscript.01.

\section{Funding}

None.

Availability of data and materials

Data sharing not applicable to this article as no datasets were generated or analysed during the current study.

Ethics approval and consent to participate

No patient related data was used; therefore, no additional statement from respective ethic committees was mandatory.

\section{Consent for publication}

Not mandatory as no datasets were generated or analysed during the current study.

\section{Competing interests}

All authors declare that they have no relationships or interests that could have direct or potential influence or impart bias on the work.

\section{Author details}

'Department of Nuclear Medicine, University Hospital, LMU Munich, Marchioninistr. 15, 81377 Munich, Germany. ${ }^{2}$ Department of Radiology, University Hospital, LMU Munich, Marchioninistr. 15, 81377 Munich, Germany. ${ }^{3}$ German Cancer Consortium (DKTK), partner site Munich; and German Cancer Research Center (DKFZ), Heidelberg, Germany. ${ }^{4}$ Department of Radiation Oncology, University Hospital, LMU Munich, Munich, Germany. ${ }^{5}$ Radiation Physics, Department of Hematology, Oncology and Radiation Physics, Skåne University Hospital, and Lund University, Lund, Sweden. ${ }^{6}$ Department of Medical Physics, School of Medicine and Public Health, University of Wisconsin-Madison, Madison, USA. ${ }^{7}$ Department of Radiation Oncology, Medical Center - University of Freiburg, Faculty of Medicine, University of Freiburg, Freiburg, Germany. ${ }^{8}$ German Cancer Consortium (DKTK), partner Site Freiburg, Freiburg, Germany.

Received: 2 January 2020 Accepted: 19 March 2020

Published online: 21 April 2020

\section{References}

1. Bernier J, Hall EJ, Giaccia A. Radiation oncology: a century of achievements. Nat Rev Cancer. 2004;4(9):737..

2. Moran JM, Elshaikh MA, Lawrence TS. Radiotherapy: what can be achieved by technical improvements in dose delivery? Lancet Oncol. 2005;6(1):51-8..

3. Bortfeld T. IMRT: a review and preview. Phys Med Biol. 2006;51(13):R363.

4. Langen K-J, Galldiks N, Hattingen E, Shah NJ. Advances in neuro-oncology imaging. Nat Rev Neurol. 2017;13(5):279..

5. Boellaard R, Delgado-Bolton R, Oyen WJG, Giammarile F, Tatsch K, Eschner W, et al. FDG PET/CT: EANM procedure guidelines for tumour imaging: version 2.0. Eur J Nucl Med Mol Imaging. 2015;42(2):328-54..

6. Maurer T, Eiber M, Schwaiger M, Gschwend JE. Current use of PSMA-PET in prostate cancer management. Nat Rev Urol. 2016;13(4):226-35.

7. Bentzen SM. Theragnostic imaging for radiation oncology: dose-painting by numbers. Lancet Oncol. 2005;6(2):112-7.

8. Brahme A, Argren A. Optimal dose distribution for eradication of heterogeneous tumors. Acta Oncol. 1987;26(5):377-85.

9. la Fougere C, Suchorska B, Bartenstein P, Kreth FW, Tonn JC. Molecular imaging of gliomas with PET: opportunities and limitations. Neuro Oncol. 2011;13(8):806-19.

10. Albert NL, Weller M, Suchorska B, Galldiks N, Soffietti R, Kim MM, et al. Response assessment in Neuro-oncology working group and European Association for Neuro-Oncology recommendations for the clinical use of PET imaging in gliomas. Neuro Oncol. 2016;18(9):1199-208. 
11. Grosu A-L, Astner ST, Riedel E, Nieder C, Wiedenmann N, Heinemann F, et al. An interindividual comparison of O-(2-[18F] Fluoroethyl)-L-Tyrosine (FET)-and L-[Methyl-11C] methionine (MET)-PET in patients with brain gliomas and metastases. Int J Radiat Oncol* Biol* Phys. 2011;81(4):1049-58.

12. Dunet $V$, Pomoni A, Hottinger A, Nicod-Lalonde M, Prior JO. Performance of 18F-FET versus 18F-FDG-PET for the diagnosis and grading of brain tumors: systematic review and meta-analysis. Neuro Oncol. 2016;18(3):426-34.

13. Suchorska B, Jansen NL, Linn J, Kretzschmar H, Janssen H, Eigenbrod S, et al. Biological tumor volume in 18FET-PET before radiochemotherapy correlates with survival in GBM. Neurology. 2015;84(7):710-9.

14. Suchorska B, Giese A, Biczok A, Unterrainer M, Weller M, Drexler M, et al. Identification of time-to-peak on dynamic 18F-FET-PET as a prognostic marker specifically in IDH1/2 mutant diffuse astrocytoma. Neuro Oncol. 2018;20(2):279-88

15. Niyazi M, Geisler J, Siefert A, Schwarz SB, Ganswindt U, Garny S, et al. FET-PET for malignant glioma treatment planning. Radiother Oncol. 2011;99(1):44-8.

16. Grosu AL, Weber WA, Franz M, Stärk S, Piert M, Thamm R, et al. Reirradiation of recurrent high-grade gliomas using amino acid PET (SPECT)/CT/MRI image fusion to determine gross tumor volume for stereotactic fractionated radiotherapy. Int J Radiat Oncol* Biol* Phys. 2005;63(2):511-9.

17. Fleischmann DF, Unterrainer $M$, Schön $R$, Corradini S, Maihöfer $C$ Bartenstein $\mathrm{P}$, et al. Margin reduction in radiotherapy for glioblastoma through 18F-fluoroethyltyrosine PET?-a recurrence pattern analysis. Radiother Oncol. 2020;145:49-55.

18. Kunz M, Thon N, Eigenbrod S, Hartmann C, Egensperger R, Herms J, et al. Hot spots in dynamic (18)FET-PET delineate malignant tumor parts within suspected WHO grade II gliomas. Neuro Oncol. 2011;13(3):307-16.

19. Lundemann M, Costa JC, Law I, Engelholm SA, Muhic A, Poulsen HS, et al. Patterns of failure for patients with glioblastoma following O-(2[(18)F]fluoroethyl)-L-tyrosine PET- and MRI-guided radiotherapy. Radiother Oncol. 2017;122(3):380-6.

20. Munck Af Rosenschold P, Costa J, Engelholm SA, Lundemann MJ, Law I, Ohlhues $\mathrm{L}$, et al. Impact of [18F]-fluoro-ethyl-tyrosine PET imaging on target definition for radiation therapy of high-grade glioma. Neuro Oncol. 2015; 17(5):757-63.

21. Niyazi M, Schnell O, Suchorska B, Schwarz SB, Ganswindt U, Geisler J, et al. FET-PET assessed recurrence pattern after radio-chemotherapy in newly diagnosed patients with glioblastoma is influenced by MGMT methylation status. Radiother Oncol. 2012;104(1):78-82.

22. Lundemann M, Af Rosenschöld PM, Muhic A, Larsen VA, Poulsen HS Engelholm S-A, et al. Feasibility of multi-parametric PET and MRI for prediction of tumour recurrence in patients with glioblastoma. Eur J Nucl Med Mol Imaging. 2019;46(3):603-13.

23. Bell C, Dowson N, Puttick S, Gal Y, Thomas P, Fay M, et al. Increasing feasibility and utility of (18)F-FDOPA PET for the management of glioma. Nucl Med Biol. 2015;42(10):788-95.

24. Pafundi DH, Laack NN, Youland RS, Parney IF, Lowe VJ, Giannini C, et al. Biopsy validation of 18F-DOPA PET and biodistribution in gliomas for neurosurgical planning and radiotherapy target delineation: results of a prospective pilot study. Neuro-oncology. 2013;15(8):1058-67.

25. Oehlke O, Mix M, Graf E, Schimek-Jasch T, Nestle U, Gotz I, et al. Amino-acid PET versus MRI guided re-irradiation in patients with recurrent glioblastoma multiforme (GLIAA) - protocol of a randomized phase II trial (NOA 10/ARO 2013-1). BMC Cancer. 2016;16(1):769.

26. Patel CB, Fazzari E, Chakhoyan A, Yao J, Raymond C, Nguyen H, et al. (18)FFDOPA PET and MRI characteristics correlate with degree of malignancy and predict survival in treatment-naive gliomas: a cross-sectional study. J Neuro-Oncol. 2018;139(2):399-409.

27. Mohile NA, Deangelis LM, Abrey LE. Utility of brain FDG-PET in primary CNS lymphoma. Clin Adv Hematol Oncol. 2008;6(11):818-20 40.

28. Brahm CG, den Hollander MW, Enting RH, de Groot JC, Solouki AM, den Dunnen WFA, et al. Serial FLT PET imaging to discriminate between true progression and pseudoprogression in patients with newly diagnosed glioblastoma: a long-term follow-up study. Eur J Nucl Med Mol Imaging. 2018;45(13):2404-12

29. Albert NL, Unterrainer M, Fleischmann DF, Lindner S, Vettermann F, Brunegraf $A$, et al. TSPO PET for glioma imaging using the novel ligand (18)F-GE-180: first results in patients with glioblastoma. Eur J Nucl Med Mol Imaging. 2017;44(13):2230-8.

30. Jensen P, Feng L, Law I, Svarer C, Knudsen GM, Mikkelsen JD, et al. TSPO imaging in Glioblastoma Multiforme: a direct comparison between 1231-
CLINDE SPECT, 18F-FET PET, and gadolinium-enhanced MR imaging. J NuCl Med. 2015:56(9):1386-90.

31. Zinnhardt $B$, Müther $M$, Roll W, Backhaus $P$, Jeibmann A, Foray $C$, et al. TSPO imaging-guided characterization of the immunosuppressive myeloid tumor microenvironment in patients with malignant glioma. Neuro Oncol. 2020.

32. Galldiks N, Stoffels G, Filss C, Rapp M, Blau T, Tscherpel C, et al. The use of dynamic O-(2-18F-fluoroethyl)-I-tyrosine PET in the diagnosis of patients with progressive and recurrent glioma. Neuro Oncol. 2015;17(9):1293-300.

33. Langen K-J, Watts C. Neuro-oncology: amino acid PET for brain tumours—ready for the clinic? Nat Rev Neurol. 2016;12(7):375.

34. Galldiks N, Langen KJ, Albert NL, Chamberlain M, Soffietti R, Kim MM, et al. PET imaging in patients with brain metastasis-report of the RANO/PET group. Neuro Oncol. 2019;21(5):585-95.

35. Galldiks N, Stoffels G, Filss CP, Piroth MD, Sabel M, Ruge Ml, et al. Role of O(2-18F-fluoroethyl)-L-tyrosine PET for differentiation of local recurrent brain metastasis from radiation necrosis. J Nucl Med. 2012;53(9):1367-74.

36. Lohmann P, Kocher M, Ceccon G, Bauer E, Stoffels G, Viswanathan S, et al. Combined FET PET/MRI radiomics differentiates radiation injury from recurrent brain metastasis. Nuklearmedizin. 2019;58(02):L6.

37. Romagna A, Unterrainer M, Schmid-Tannwald C, Brendel M, Tonn J-C, Nachbichler SB, et al. Suspected recurrence of brain metastases after focused high dose radiotherapy: can [18 F] FET-PET overcome diagnostic uncertainties? Radiat Oncol. 2016;11(1):139.

38. Unterrainer M, Niyazi M, Tonn J, Ilhan H, Bartenstein P, Albert N. Current status of SSR-directed imaging and therapy in meningioma. Clin Transl Imaging. 2019:1-10

39. Unterrainer M, Niyazi M, Tonn J, Ithan H, Bartenstein P, Albert N. A look ahead: future directions of SSR-directed imaging and therapy in meningioma. Clin Transl Imaging. 2019;7(5):357-62.

40. Rachinger W, Stoecklein VM, Terpolilli NA, Haug AR, Ertl L, Poschl J, et al. Increased 68Ga-DOTATATE uptake in PET imaging discriminates meningioma and tumor-free tissue. J Nucl Med. 2015;56(3):347-53.

41. Gehler B, Paulsen F, Oksuz MO, Hauser TK, Eschmann SM, Bares R, et al. [68Ga]-DOTATOC-PET/CT for meningioma IMRT treatment planning. Radiat Oncol. 2009;4:56.

42. Milker-Zabel S, Zabel-du Bois A, Henze M, Huber P, Schulz-Ertner D, Hoess A, et al. Improved target volume definition for fractionated stereotactic radiotherapy in patients with intracranial meningiomas by correlation of $C T$, MRI, and [68Ga]-DOTATOC-PET. Int J Radiat Oncol Biol Phys. 2006;65(1):2227.

43. Kunz WG, Jungblut LM, Kazmierczak PM, Vettermann FJ, Bollenbacher A, Tonn JC, et al. Improved detection of Transosseous Meningiomas using (68)Ga-DOTATATE PET/CT compared with contrast-enhanced MRI. J Nucl Med. 2017:58(10):1580-7.

44. Astner ST, Dobrei-Ciuchendea M, Essler M, Bundschuh RA, Sai H, Schwaiger $M$, et al. Effect of 11C-methionine-positron emission tomography on gross tumor volume delineation in stereotactic radiotherapy of skull base meningiomas. Int J Radiat Oncol Biol Phys. 2008;72(4):1161-7.

45. Kawai N, Miyake K, Okada M, Yamamoto Y, Nishiyama Y, Tamiya T. Usefulness and limitation of FDG-PET in the diagnosis of primary central nervous system lymphoma. No Shinkei Geka. 2013;41(2):117-26.

46. Galldiks N, Albert NL, Sommerauer M, Grosu AL, Ganswindt U, Law I, et al. PET imaging in patients with meningioma - report of the RANO/PET group. Neuro Oncol. 2017;19(12):1576-87.

47. Wright $C L$, Washington $I R$, Bhatt $A D$, Knopp MV. Emerging opportunities for digital PET/CT to advance Locoregional therapy in head and neck Cancer. Semin Radiat Oncol. 2019;29(2):93-101.

48. Goel R, Moore W, Sumer B, Khan S, Sher D, Subramaniam RM. Clinical practice in PET/CT for the Management of Head and Neck Squamous Cell Cancer. AJR Am J Roentgenol. 2017;209(2):289-303.

49. Pedraza S, Ruiz-Alonso A, Hernández-Martínez AC, Cabello E, Lora D, PérezRegadera JF. 18F-FDG PET/CT in staging and delineation of radiotherapy volume for head and neck cancer. Rev Esp Med Nucl. 2019;38(3):154-9.

50. van den Bosch S, Vogel W, Raaijmakers CP, Dijkema T, Terhaard CHJ, AlMamgani A, et al. Implications of improved diagnostic imaging of small nodal metastases in head and neck cancer: radiotherapy target volume transformation and dose de-escalation. Radiother Oncol. 2018;128(3):472-8.

51. Gregoire V, Lefebvre JL, Licitra L, Felip E, EHNS-ESMO-ESTRO guidelines working group. Squamous cell carcinoma of the head and neck: EHNSESMO-ESTRO clinical practice guidelines for diagnosis, treatment and followup. Ann Oncol. 2010;21(Suppl 5):v184-6. 
52. Verma V, Choi Jl, Sawant A, Gullapalli RP, Chen W, Alavi A, et al. Use of PET and other functional imaging to guide target delineation in radiation oncology. Semin Radiat Oncol. 2018;28(3):171-7.

53. Birk Christensen C, Loft-Jakobsen A, Munck af Rosenschöld P, Højgaard L, Roed H, Berthelsen AK. 18F-FDG PET/CT for planning external beam radiotherapy alters therapy in $11 \%$ of 581 patients. Clin Physiol Funct Imaging. 2018;38(2):278-84

54. van den Bosch S, Doornaert PAH, Dijkema T, Zwijnenburg EM, Verhoef LCG, Hoeben BAW, et al. (18)F-FDG-PET/CT-based treatment planning for definitive (chemo)radiotherapy in patients with head and neck squamous cell carcinoma improves regional control and survival. Radiother Oncol. 2019.

55. Martens RM, Noij DP, Koopman T, Zwezerijnen B, Heymans M, de Jong MC, et al. Predictive value of quantitative diffusion-weighted imaging and 18-FFDG-PET in head and neck squamous cell carcinoma treated by (chemo)radiotherapy. Eur J Radiol. 2019;113:39-50.

56. Cheng NM, Hsieh CE, Liao CT, Ng SH, Wang HM, Fang YD, et al. Prognostic value of tumor heterogeneity and SUVmax of pretreatment 18F-FDG PET/CT for salivary gland carcinoma with high-risk histology. Clin Nucl Med. 2019; 44(5):351-8

57. Fujima N, Hirata K, Shiga T, Li R, Yasuda K, Onimaru R, et al. Integrating quantitative morphological and intratumoural textural characteristics in FDG-PET for the prediction of prognosis in pharynx squamous cell carcinoma patients. Clin Radiol. 2018;73(12):1059 e1-8.

58. Ger RB, Zhou S, Elgohari B, Elhalawani H, Mackin DM, Meier JG, et al. Radiomics features of the primary tumor fail to improve prediction of overall survival in large cohorts of CT- and PET-imaged head and neck cancer patients. PLoS One. 2019;14(9):e0222509.

59. Feliciani G, Fioroni F, Grassi E, Bertolini M, Rosca A, Timon G, et al. Radiomic profiling of head and neck Cancer: 18F-FDG PET texture analysis as predictor of patient survival. Contrast Media Mol Imaging. 2018;2018: 3574310.

60. Crispin-Ortuzar M, Apte A, Grkovski M, Oh JH, Lee NY, Schoder H, et al. Predicting hypoxia status using a combination of contrast-enhanced computed tomography and [(18)F]-Fluorodeoxyglucose positron emission tomography radiomics features. Radiother Oncol. 2018;127(1):36-42.

61. Fleming IN, Manavaki R, Blower PJ, West C, Williams KJ, Harris AL, et al. Imaging tumour hypoxia with positron emission tomography. $\mathrm{Br} J$ Cancer. 2015;112(2):238-50.

62. Thorwarth D, Welz S, Monnich D, Pfannenberg C, Nikolaou K, Reimold M, et al. Prospective evaluation of a tumor control probability model based on dynamic (18)F-FMISO PET for head-and-neck cancer radiotherapy. J Nucl Med. 2019.

63. Welz S, Monnich D, Pfannenberg C, Nikolaou K, Reimold M, La Fougere C, et al. Prognostic value of dynamic hypoxia PET in head and neck cancer: results from a planned interim analysis of a randomized phase II hypoxiaimage guided dose escalation trial. Radiother Oncol. 2017;124(3):526-32.

64. Betts HM, O'Connor RA, Christian JA, Vinayakamoorthy V, Foweraker K, Pascoe AC, et al. Hypoxia imaging with [18F]HX4 PET in squamous cell head and neck cancers: a pilot study for integration into treatment planning. Nucl Med Commun. 2019;40(1):73-8.

65. Wiedenmann N, Bunea $H$, Rischke HC, Bunea A, Majerus L, Bielak L, et al. Effect of radiochemotherapy on T2* MRI in HNSCC and its relation to FMISO PET derived hypoxia and FDG PET. Radiat Oncol. 2018;13(1):159.

66. Wiedenmann NE, Bucher S, Hentschel M, Mix M, Vach W, Bittner M-I, et al. Serial [18F]-fluoromisonidazole PET during radiochemotherapy for locally advanced head and neck cancer and its correlation with outcome. Radiother Oncol. 2015;117(1):113-7.

67. Zips D, Zöphel K, Abolmaali N, Perrin R, Abramyuk A, Haase R, et al. Exploratory prospective trial of hypoxia-specific PET imaging during radiochemotherapy in patients with locally advanced head-and-neck cancer. Radiother Oncol. 2012;105(1):21-8.

68. Monnich D, Thorwarth D, Leibfarth S, Pfannenberg C, Reischl G, Mauz PS, et al. Overlap of highly FDG-avid and FMISO hypoxic tumor subvolumes in patients with head and neck cancer. Acta Oncol. 2017;56(11):1577-82.

69. Kroenke M, Hirata K, Gafita A, Watanabe S, Okamoto S, Magota K, et al. Voxel based comparison and texture analysis of 18F-FDG and 18F-FMISO PET of patients with head-and-neck cancer. PLoS One. 2019;14(2):e0213111.

70. Chen L, Zhang Z, Kolb HC, Walsh JC, Zhang J, Guan Y. (1)(8)F-HX4 hypoxia imaging with PET/CT in head and neck cancer: a comparison with (1)(8)FFMISO. Nucl Med Commun. 2012;33(10):1096-102.
71. Poeppel TD, Binse I, Petersenn S, Lahner H, Schott M, Antoch G, et al. 68GaDOTATOC versus 68Ga-DOTATATE PET/CT in functional imaging of neuroendocrine tumors. J Nucl Med. 2011;52(12):1864-70.

72. Khor LK, Loi HY, Sinha AK, Tong KT, Goh BC, Loh KS, et al. (68)Ga-DOTApeptide: a novel molecular biomarker for nasopharyngeal carcinoma. Head Neck. 2016;38(4):E76-80.

73. Unterrainer M, Maihoefer C, Cyran CC, Bartenstein P, Niyazi M, Albert NL. 68Ga-DOTATATE PET/CT reveals Epstein-Barr virus-associated nasopharyngeal carcinoma in a case of suspected sphenoid wing meningioma. Clin Nucl Med. 2018;43(4):287-8.

74. Schartinger VH, Dudas J, Url C, Reinold S, Virgolini IJ, Kroiss A, et al. (68)GaDOTA (0)-Tyr (3)-octreotide positron emission tomography in nasopharyngeal carcinoma. Eur J Nucl Med Mol Imaging. 2015;42(1):20-4.

75. Morgan $\mathrm{R}$, Chin BB, Lanning R. Feasibility of rapid integrated radiation therapy planning with follow-up FDG PET/CT to improve overall treatment assessment in head and neck cancer. Am J Nucl Med Mol Imaging. 2019; 9(1):24-9.

76. Brun E, Kjellén E, Tennvall J, Ohlsson T, Sandell A, Perfekt R, et al. FDG PET studies during treatment: prediction of therapy outcome in head and neck squamous cell carcinoma. Head Neck. 2002;24(2):127-35.

77. Martens RM, Noij DP, Ali M, Koopman T, Marcus JT, Vergeer MR, et al. Functional imaging early during (chemo)radiotherapy for response prediction in head and neck squamous cell carcinoma; a systematic review. Oral Oncol. 2019;88:75-83.

78. Kim S, Oh S, Kim JS, Kim YK, Kim KH, Oh DH, et al. Prognostic value of FDG PET/CT during radiotherapy in head and neck cancer patients. Radiat Oncol J. 2018;36(2):95-102.

79. Galiz, a Barbosa F, Riesterer O, Tanadini-Lang S, Stieb S, Studer G, Pruschy M, et al. Evaluation of 18F-FDG PET/CT as an early imaging biomarker for response monitoring after radiochemotherapy using cetuximab in head and heck squamous cell carcinoma. Head Neck. 2019.

80. Mehanna H, Wong WL, McConkey CC, Rahman JK, Robinson M, Hartley AG, et al. PET-CT surveillance versus neck dissection in advanced head and neck Cancer. N Engl J Med. 2016;374(15):1444-54.

81. Fatehi KS, Thiagarajan S, Dhar H, Purandare N, DC AK, Chaukar D, et al. Utility of response assessment PET-CT to predict residual disease in neck nodes: a comparison with the histopathology. Auris Nasus Larynx. 2019; 46(4):599-604

82. Kim R, Ock CY, Keam B, Kim TM, Kim JH, Paeng JC, et al. Predictive and prognostic value of PET/CT imaging post-chemoradiotherapy and clinical decision-making consequences in locally advanced head \& neck squamous cell carcinoma: a retrospective study. BMC Cancer. 2016;16:116.

83. Driessen JP, Peltenburg B, Philippens MEP, Huijbregts JE, Pameijer FA, de Bree $\mathrm{R}$, et al. Prospective comparative study of MRI including diffusionweighted images versus FDG PET-CT for the detection of recurrent head and neck squamous cell carcinomas after (chemo)radiotherapy. Eur J Radiol. 2019;111:62-7.

84. Wong ET, Dmytriw AA, Yu E, Waldron J, Lu L, Fazelzad R, et al. (18) F-FDG PET/CT for locoregional surveillance following definitive treatment of head and neck cancer: a meta-analysis of reported studies. Head Neck. 2019;41(2): 551-61.

85. Sheikhbahaei S, Taghipour M, Ahmad R, Fakhry C, Kiess AP, Chung CH, et al. Diagnostic accuracy of follow-up FDG PET or PET/CT in patients with head and neck Cancer after definitive treatment: a systematic review and metaanalysis. AJR Am J Roentgenol. 2015;205(3):629-39.

86. Li Y, Awan MJ, Chang T, Lavertu P, Zender C, Rezaee R, et al. Postradiotherapy $\mathrm{PET} / \mathrm{CT}$ for predicting treatment outcomes in head and neck cancer after postoperative radiotherapy. Eur J Nucl Med Mol Imaging. 2019; 46(4):794-800.

87. Bray F, Ferlay J, Soerjomataram I, Siegel RL, Torre LA, Jemal A. Global cancer statistics 2018: GLOBOCAN estimates of incidence and mortality worldwide for 36 cancers in 185 countries. CA Cancer J Clin. 2018;68(6):394-424.

88. Siegel RL, Miller KD, Jemal A. Cancer statistics, 2019. CA Cancer J Clin. 2019; 69(1):7-34.

89. Gregory DL, Hicks RJ, Hogg A, Binns DS, Shum PL, Milner A, et al. Effect of PET/CT on management of patients with non-small cell lung cancer: results of a prospective study with 5-year survival data. J Nucl Med. 2012;53(7): 1007-15.

90. Fischer B, Lassen U, Mortensen J, Larsen S, Loft A, Bertelsen A, et al. Preoperative staging of lung cancer with combined PET-CT. N Engl J Med. 2009;361(1):32-9. 
91. van Tinteren $H$, Hoekstra OS, Smit EF, van den Bergh JH, Schreurs AJ, Stallaert RA, et al. Effectiveness of positron emission tomography in the preoperative assessment of patients with suspected non-small-cell lung cancer: the PLUS multicentre randomised trial. Lancet. 2002;359(9315):138892.

92. Gould MK, Kuschner WG, Rydzak CE, Maclean CC, Demas AN, Shigemitsu H, et al. Test performance of positron emission tomography and computed tomography for mediastinal staging in patients with non-small-cell lung cancer: a meta-analysis. Ann Intern Med. 2003;139(11):879-92.

93. Antoch G, Stattaus J, Nemat AT, Marnitz S, Beyer T, Kuehl H, et al. Non-small cell lung cancer: dual-modality PET/CT in preoperative staging. Radiology. 2003;229(2):526-33.

94. Cerfolio RJ, Ojha B, Bryant AS, Raghuveer V, Mountz JM, Bartolucci AA. The accuracy of integrated PET-CT compared with dedicated PET alone for the staging of patients with nonsmall cell lung cancer. Ann Thorac Surg. 2004 78(3):1017-23.

95. De Wever W, Ceyssens S, Mortelmans L, Stroobants S, Marchal G, Bogaert J, et al. Additional value of PET-CT in the staging of lung cancer: comparison with CT alone, PET alone and visual correlation of PET and CT. Eur Radiol. 2007;17(1):23-32.

96. Lardinois D, Weder W, Hany TF, Kamel EM, Korom S, Seifert B, et al. Staging of non-small-cell lung cancer with integrated positron-emission tomography and computed tomography. N Engl J Med. 2003;348(25):25007.

97. Shim SS, Lee KS, Kim B-T, Chung MJ, Lee EJ, Han J, et al. Non-small cell lung cancer: prospective comparison of integrated FDG PET/CT and CT alone for preoperative staging. Radiology. 2005;236(3):1011-9.

98. Kirchner J, Sawicki LM, Nensa F, Schaarschmidt BM, Reis H, Ingenwerth M, et al. Prospective comparison of 18 F-FDG PET/MRI and 18 F-FDG PET/CT for thoracic staging of non-small cell lung cancer. Eur J Nucl Med Mol Imaging. 2019;46(2):437-45.

99. Schaarschmidt B, Buchbender C, Gomez B, Rubbert C, Hild F, Köhler J, et al. Thoracic staging of non-small-cell lung cancer using integrated 18 F-FDG PET/MR imaging: diagnostic value of different MR sequences. Eur J Nucl Med Mol Imaging. 2015;42(8):1257-67.

100. Schaarschmidt BM, Grueneisen J, Metzenmacher M, Gomez B, Gauler T, Roesel C, et al. Thoracic staging with 18 F-FDG PET/MR in non-small cell lung cancer-does it change therapeutic decisions in comparison to $18 \mathrm{~F}$ FDG PET/CT? Eur Radiol. 2017;27(2):681-8.

101. Ganem J, Thureau S, Gardin I, Modzelewski R, Hapdey S, Vera P. Delineation of lung cancer with FDG PET/CT during radiation therapy. Radiat Oncol. 2018;13(1):219.

102. Van Baardwijk A, Bosmans G, Boersma L, Buijsen J, Wanders S, Hochstenbag $\mathrm{M}$, et al. Pet-ct-based auto-contouring in non-small-cell lung cancer correlates with pathology and reduces interobserver variability in the delineation of the primary tumor and involved nodal volumes. Int J Radiat Onco* ${ }^{*}$ Biol* Phys. 2007;68(3):771-8

103. Ung YC, Bezjak A, Coakley N, Evans WK. Positron emission tomography with 18fluorodeoxyglucose in radiation treatment planning for non-small cell lung cancer: a systematic review. J Thorac Oncol. 2011;6(1):86-97.

104. Hallqvist A, Alverbratt C, Strandell A, Samuelsson O, Björkander E, Liljegren A, et al. Positron emission tomography and computed tomographic imaging (PET/CT) for dose planning purposes of thoracic radiation with curative intent in lung cancer patients: a systematic review and metaanalysis. Radiother Oncol. 2017;123(1):71-7.

105. Konert T, Vogel W, MacManus MP, Nestle U, Belderbos J, Grégoire V, et al. $\mathrm{PET} / \mathrm{CT}$ imaging for target volume delineation in curative intent radiotherapy of non-small cell lung cancer: IAEA consensus report 2014. Radiother Oncol. 2015;116(1):27-34.

106. Pöttgen C, Gauler T, Bellendorf A, Guberina M, Bockisch A, Schwenzer N, et al. Standardized uptake decrease on [18F]-fluorodeoxyglucose positron emission tomography after neoadjuvant chemotherapy is a prognostic classifier for long-term outcome after multimodality treatment: secondary analysis of a randomized trial for resectable stage IIIA/B non-small-cell lung cancer. J Clin Oncol. 2016;34(21):2526-33.

107. Antonia SJ, Villegas A, Daniel D, Vicente D, Murakami S, Hui R, et al. Overall survival with durvalumab after chemoradiotherapy in stage III NSCLC. N Engl J Med. 2018;379(24):2342-50.

108. Antonia SJ, Villegas A, Daniel D, Vicente D, Murakami S, Hui R, et al. Durvalumab after chemoradiotherapy in stage III non-small-cell lung cancer. N Engl J Med. 2017;377(20):1919-29.
109. Früh M, De Ruysscher D, Popat S, Crinò L, Peters S, Felip E, et al. Small-cell lung cancer (SCLC): ESMO Clinical Practice Guidelines for diagnosis, treatment and follow-up. Ann Oncol. 2013;24(suppl_6):vi99-vi105.

110. Bradley JD, Dehdashti F, Mintun MA, Govindan R, Trinkaus K, Siegel BA. Positron emission tomography in limited-stage small-cell lung cancer: a prospective study. J Clin Oncol. 2004;22(16):3248-54.

111. Kim H, Yoo IR, Boo SH, Park HL, Kim SH. Prognostic value of pre-and posttreatment FDG PET/CT parameters in small cell lung cancer patients. Nucl Med Mol Imaging. 2018;52(1):31-8.

112. Ruben JD, Ball DL. The efficacy of PET staging for small-cell lung cancer: a systematic review and cost analysis in the Australian setting. J Thorac Oncol. 2012;7(6):1015-20.

113. Zer A, Domachevsky L, Rapson Y, Nidam M, Flex D, Allen A, et al. The role of 18F-FDG PET/CT on staging and prognosis in patients with small cell lung cancer. Eur Radiol. 2016;26(9):3155-61.

114. Manoharan P, Salem A, Mistry H, Gornall M, Harden S, Julyan P, et al. 18FFludeoxyglucose PET/CT in SCLC: analysis of the CONVERT randomized controlled trial. J Thorac Oncol. 2019.

115. Cremonesi M, Gilardi L, Ferrari ME, Piperno G, Travaini LL, Timmerman R et al. Role of interim 18 F-FDG-PET/CT for the early prediction of clinical outcomes of non-small cell lung cancer (NSCLC) during radiotherapy or chemo-radiotherapy. A systematic review. Eur J Nucl Med Mol Imaging. 2017;44(11):1915-27.

116. Kong F-M, Ten Haken RK, Schipper M, Frey KA, Hayman J, Gross M, et al. Effect of midtreatment PET/CT-adapted radiation therapy with concurrent chemotherapy in patients with locally advanced non-small-cell lung cancer: a phase 2 clinical trial. JAMA Oncol. 2017;3(10):1358-65.

117. Ohri N, Bodner WR, Halmos B, Cheng H, Perez-Soler R, Keller SM, et al. 18Ffluorodeoxyglucose/positron emission tomography predicts patterns of failure after definitive chemoradiation therapy for locally advanced nonsmall cell lung cancer. Int J Radiat Oncol* Biol* Phys. 2017;97(2):372-80.

118. Roengvoraphoj O, Wijaya C, Eze C, Li M, Dantes M, Taugner J, et al. Analysis of primary tumor metabolic volume during chemoradiotherapy in locally advanced non-small cell lung cancer. Strahlenther Onkol. 2018;194(2):10715.

119. Roengvoraphoj O, Eze C, Wijaya C, Dantes M, Taugner J, Tufman A, et al. How much primary tumor metabolic volume reduction is required to improve outcome in stage III NSCLC after chemoradiotherapy? A singleCentre experience. Eur J Nucl Med Mol Imaging. 2018;45(12):2103-9.

120. Hope TA, Goodman JZ, Allen IE, Calais J, Fendler WP, Carroll PR. Metaanalysis of 68Ga-PSMA-11 PET accuracy for the detection of prostate Cancer validated by histopathology. J Nucl Med. 2019;60(6):786-93.

121. Krohn T, Verburg FA, Pufe T. [(68)Ga]PSMA-HBED uptake mimicking lymph node metastasis in coeliac ganglia: an important pitfall in clinical practice. Eur J Nucl Med Mol Imaging. 2015;42.

122. Dias AH, Holm Vendelbo M, Bouchelouche K. Prostate-Specific Membrane Antigen PET/CT: Uptake in Lymph Nodes With Active Sarcoidosis. Clin Nucl Med. 2017:42(3)

123. Perera M, Papa N, Christidis D, Wetherell D, Hofman MS, Murphy DG, et al. Sensitivity, Specificity, and Predictors of Positive $<$ sup $>68</$ sup $>$ GaProstate-specific Membrane Antigen Positron Emission Tomography in Advanced Prostate Cancer: A Systematic Review and Meta-analysis. Eur Urol. 70(6):926-37.

124. Zamboglou C, Drendel V, Jilg CA, Rischke HC, Beck TI, Schultze-Seemann W, et al. Comparison of 68Ga-HBED-CC PSMA-PET/CT and multiparametric MRI for gross tumour volume detection in patients with primary prostate cancer based on slice by slice comparison with histopathology. Theranostics. 2017;7(1):228.

125. Zamboglou C, Klein CM, Thomann B, Fassbender TF, Rischke HC, Kirste S, et al. The dose distribution in dominant intraprostatic tumour lesions defined by multiparametric MRI and PSMA PET/CT correlates with the outcome in patients treated with primary radiation therapy for prostate cancer. Radiat Oncol. 2018;13(1):65

126. Budäus L, Leyh-Bannurah SR, Salomon G, Michl U, Heinzer H, Huland H, et al. Initial experience of (68)Ga-PSMA PET/CT imaging in high-risk prostate Cancer patients Prior to radical prostatectomy. Eur Urol. 2016;69(3):393-6.

127. van Leeuwen PJ, Emmett L, Ho B, Delprado W, Ting F, Nguyen Q, et al. Prospective evaluation of $68 \mathrm{Gallium}$-prostate-specific membrane antigen positron emission tomography/computed tomography for preoperative lymph node staging in prostate cancer. BJU Int. 2017;119(2):209-15.

128. De Bleser E, Jereczek-Fossa BA, Pasquier D, Zilli T, Van As N, Siva S, et al. Metastasis-directed Therapy in Treating Nodal Oligorecurrent Prostate 
Cancer: A Multi-institutional Analysis Comparing the Outcome and Toxicity of Stereotactic Body Radiotherapy and Elective Nodal Radiotherapy. Eur Urol. 2019

129. De Bruycker A, De Bleser E, Decaestecker K, Fonteyne V, Lumen N, De Visschere $P$, et al. Nodal Oligorecurrent prostate Cancer: anatomic pattern of possible treatment failure in relation to elective surgical and radiotherapy treatment templates. Eur Urol. 2019;75(5):826-33.

130. Pyka T, Okamoto S, Dahlbender M, Tauber R, Retz M, Heck M, et al. Comparison of bone scintigraphy and 68Ga-PSMA PET for skeletal staging in prostate cancer. Eur J Nucl Med Mol Imaging. 2016;43(12):2114-21.

131. Thomas L, Balmus C, Ahmadzadehfar H, Essler M, Strunk H, Bundschuh RA. Assessment of Bone Metastases in Patients with Prostate Cancer-A Comparison between. Pharmaceuticals (Basel). 2017;10(3).

132. Freitag MT, Radtke JP, Hadaschik BA, Kopp-Schneider A, Eder M, Kopka K, et al. Comparison of hybrid 68Ga-PSMA PET/MRI and 68Ga-PSMA PET/CT in the evaluation of lymph node and bone metastases of prostate cancer. Eur J Nucl Med Mol Imaging. 2016;43(1):70-83.

133. Schmidt-Hegemann N-S, Chukwuka E, Minglun L, Rogowski P, Schaefer C, Stief $\mathrm{C}$, et al. Impact of $68 \mathrm{Ga}-\mathrm{PSMA}-\mathrm{PET} / \mathrm{CT}$ on the radiotherapeutic approach for prostate cancer in comparison to $\mathrm{CT}$ - a retrospective analysis. J Nucl Med. 2018.

134. Roach PJ, Francis R, Emmett L, Hsiao E, Kneebone A, Hruby G, et al. The impact of 68Ga-PSMA PET/CT on management intent in prostate Cancer: results of an Australian prospective multicenter study. J Nucl Med. 2018; 59(1):82-8.

135. Mottet N, van den Bergh RCN, Briers E. EAU-EANM-ESTRO-ESUR-SIOG Guidelines on Prostate Cancer. Eur Assoc Urol. 2019;75(6):889-90.

136. Fendler WP, Calais J, Eiber M, Flavell RR, Mishoe A, Feng FY, et al. Assessment of 68Ga-PSMA-11 PET accuracy in localizing recurrent prostate Cancer: a prospective single-arm clinical trial. JAMA Oncol. 2019;5(6):856-63.

137. Calais J, Fendler WP, Eiber M, Gartmann J, Chu F-I, Nickols NG, et al. Impact of 68Ga-PSMA-11 PET/CT on the Management of Prostate Cancer Patients with biochemical recurrence. J Nucl Med. 2018;59(3):434-41.

138. Calais J, Czernin J, Cao M, Kishan AU, Hegde JV, Shaverdian N, et al. 68GaPSMA PET/CT mapping of prostate cancer biochemical recurrence following radical prostatectomy in 270 patients with $P S A<1.0 \mathrm{ng} / \mathrm{ml}$ : Impact on Salvage Radiotherapy Planning. J Nucl Med. 2017.

139. Calais J, Czernin J, Fendler WP, Elashoff D, Nickols NG. Randomized prospective phase III trial of (68)Ga-PSMA-11 PET/CT molecular imaging for prostate cancer salvage radiotherapy planning [PSMA-SRT]. BMC Cancer. 2019;19(1):1-11

140. Henkenberens C, Klot CA, Ross TL. 68Ga-PSMA ligand PET/CT-based radiotherapy in locally recurrent and recurrent oligometastatic prostate cancer: early efficacy after primary therapy. Strahlenther Onkol. 2016;192.

141. Zschaeck S, Wust P, Beck M, Wlodarczyk W, Kaul D, Rogasch J, et al. Intermediate-term outcome after PSMA-PET guided high-dose radiotherapy of recurrent high-risk prostate cancer patients. Radiat Oncol. 2017;12(1):140.

142. Emmett L, Van Leeuwen P, Nandurkar R, Scheltema MJ, Cusick T, Hruby G, et al. Treatment outcomes from (68)GaPSMA PET CT informed salvage radiation treatment in men with rising PSA following radical prostatectomy: Prognostic value of a negative PSMA PET. J Nucl Med. 2017;58(12):1972-6.

143. Schmidt-Hegemann N-S, Fendler WP, Ilhan H, Herlemann A, Buchner A, Stief $C$, et al. Outcome after PSMA PET/CT based radiotherapy in patients with biochemical persistence or recurrence after radical prostatectomy. Radiat Oncol. 2018;13(1):37.

144. Schmidt-Hegemann N-S, Stief C, Kim T-H, Eze C, Kirste S, Strouthos I, et al. Outcome after PSMA PET/CT-based salvage radiotherapy in patients with biochemical recurrence after radical prostatectomy: a 2-institution retrospective analysis. J Nucl Med. 2019;60(2):227-33.

145. Zamboglou C, Fassbender TF, Steffan L, Schiller F, Fechter T, Carles M, et al. Validation of different PSMA-PET/CT-based contouring techniques for intraprostatic tumor definition using histopathology as standard of reference. Radiother Oncol. 2019.

146. Thomas L, Kantz S, Hung A, Monaco D, Gaertner FC, Essler M, et al. 68GaPSMA-PET/CT imaging of localized primary prostate cancer patients for intensity modulated radiation therapy treatment planning with integrated boost. Eur J Nucl Med Mol Imaging. 2018;45(7):1170-8.

147. Bettermann AS, Zamboglou C, Kiefer S, Jilg CA, Spohn S, Kranz-Rudolph J, et al. [<sup $>68</$ sup $>$ Ga-]PSMA-11 PET/CT and multiparametric MRI for gross tumor volume delineation in a slice by slice analysis with whole mount histopathology as a reference standard - implications for focal radiotherapy planning in primary prostate cancer. Radiother Oncol.

148. Zamboglou C, Carles M, Fechter T, Kiefer S, Reichel K, Fassbender TF, et al. Radiomic features from PSMA PET for non-invasive intraprostatic tumor discrimination and characterization in patients with intermediate-and highrisk prostate cancer-a comparison study with histology reference. Theranostics. 2019;9(9):2595.

149. Parker CC, James ND, Brawley CD, Clarke NW, Hoyle AP, Ali A, et al. Radiotherapy to the primary tumour for newly diagnosed, metastatic prostate cancer (STAMPEDE): a randomised controlled phase 3 trial. Lancet. 2018;392(10162):2353-66.

150. Ost P, Reynders D, Decaestecker K, Fonteyne V, Lumen N, De Bruycker A, et al. Surveillance or metastasis-directed therapy for Oligometastatic prostate Cancer recurrence: a prospective, randomized, multicenter phase II trial. J Clin Oncol. 2017;36(5):446-53.

151. Strosberg J, El-Haddad G, Wolin E, Hendifar A, Yao J, Chasen B, et al. Phase 3 trial of 177Lu-Dotatate for midgut neuroendocrine tumors. N Engl J Med. 2017;376(2):125-35.

152. Hofman MS, Violet J, Hicks RJ, Ferdinandus J, Thang SP, Akhurst T, et al. [< sup $>177<$ /sup $>$ Lu]-PSMA-617 radionuclide treatment in patients with metastatic castration-resistant prostate cancer (LuPSMA trial): a singleCentre, single-arm, phase 2 study. Lancet Oncol. 2018;19(6):825-33.

153. Bedenne L, Michel P, Bouche O, Milan C, Mariette C, Conroy T, et al. Chemoradiation followed by surgery compared with chemoradiation alone in squamous cancer of the esophagus: FFCD 9102. J Clin Oncol. 2007;25(10): $1160-8$.

154. Li Y, Zschaeck S, Lin Q, Chen S, Chen L, Wu H. Metabolic parameters of sequential 18F-FDG PET/CT predict overall survival of esophageal cancer patients treated with (chemo-) radiation. Radiat Oncol. 2019;14(1):35.

155. Butof R, Hofheinz F, Zophel K, Schmollack J, Jentsch C, Zschaeck S, et al. Prognostic value of SUR in patients with trimodality treatment of locally advanced esophageal carcinoma. J Nucl Med. 2018.

156. Leong T, Everitt C, Yuen K, Condron S, Hui A, Ngan SY, et al. A prospective study to evaluate the impact of FDG-PET on CT-based radiotherapy treatment planning for oesophageal cancer. Radiother Oncol. 2006;78(3): 254-61.

157. Jimenez-Jimenez E, Mateos P, Aymar N, Roncero R, Ortiz I, Gimenez M, et al. Radiotherapy volume delineation using 18F-FDG-PET/CT modifies gross node volume in patients with oesophageal cancer. Clin Transl Oncol. 2018; 20(11):1460-6.

158. Machiels M, Wouterse SJ, Geijsen ED, van Os RM, Bennink RJ, van Laarhoven HW, et al. Distribution of lymph node metastases on FDG-PET/CT in inoperable or unresectable oesophageal cancer patients and the impact on target volume definition in radiation therapy. J Med Imaging Radiat Oncol. 2016;60(4):520-7.

159. Wu AJ, Bosch WR, Chang DT, Hong TS, Jabbour SK, Kleinberg LR, et al. Expert consensus contouring guidelines for intensity modulated radiation therapy in esophageal and Gastroesophageal junction Cancer. Int J Radiat Oncol Biol Phys. 2015:92(4):911-20.

160. Reyngold M, Parikh P, Crane CH. Ablative radiation therapy for locally advanced pancreatic cancer: techniques and results. Radiat Oncol. 2019; 14(1):95.

161. Olberg S, Green O, Cai B, Yang D, Rodriguez V, Zhang H, et al. Optimization of treatment planning workflow and tumor coverage during daily adaptive magnetic resonance image guided radiation therapy (MR-IGRT) of pancreatic cancer. Radiat Oncol. 2018;13(1):51.

162. Quon A, Chang ST, Chin F, Kamaya A, Dick DW, Loo BW Jr, et al. Initial evaluation of 18F-fluorothymidine (FLT) PET/CT scanning for primary pancreatic cancer. Eur J Nucl Med Mol Imaging. 2008;35(3):527-31.

163. Ford EC, Herman J, Yorke E, Wahl RL. 18F-FDG PET/CT for image-guided and intensity-modulated radiotherapy. J Nucl Med. 2009;50(10):1655-65.

164. Schellenberg D, Quon A, Minn AY, Graves EE, Kunz P, Ford JM, et al, 18Fluorodeoxyglucose PET is prognostic of progression-free and overall survival in locally advanced pancreas cancer treated with stereotactic radiotherapy. Int J Radiat Oncol Biol Phys. 2010;77(5):1420-5.

165. Dholakia AS, Chaudhry M, Leal JP, Chang DT, Raman SP, Hacker-Prietz A et al. Baseline metabolic tumor volume and total lesion glycolysis are associated with survival outcomes in patients with locally advanced pancreatic cancer receiving stereotactic body radiation therapy. Int J Radiat Oncol Biol Phys. 2014;89(3):539-46. 
166. Mellon EA, Jin WH, Frakes JM, Centeno BA, Strom TJ, Springett GM, et al. Predictors and survival for pathologic tumor response grade in borderline resectable and locally advanced pancreatic cancer treated with induction chemotherapy and neoadjuvant stereotactic body radiotherapy. Acta Oncol. 2017:56(3):391-7.

167. Maas M, Nelemans PJ, Valentini V, Das P, Rodel C, Kuo LJ, et al. Long-term outcome in patients with a pathological complete response after chemoradiation for rectal cancer: a pooled analysis of individual patient data. Lancet Oncol. 2010;11(9):835-44.

168. Appelt AL, Ploen J, Vogelius IR, Bentzen SM, Jakobsen A. Radiation doseresponse model for locally advanced rectal cancer after preoperative chemoradiation therapy. Int J Radiat Oncol Biol Phys. 2013;85(1):74-80.

169. Burbach JP, den Harder AM, Intven M, van Vulpen $M$, Verkooijen HM, Reerink O. Impact of radiotherapy boost on pathological complete response in patients with locally advanced rectal cancer: a systematic review and meta-analysis. Radiother Oncol. 2014;113(1):1-9.

170. Kleijnen JJE, van Asselen B, Intven M, Burbach JPM, Philippens MEP, Lagendijk JJW, et al. Does setup on rectal wall improve rectal cancer boost radiotherapy? Radiat Oncol. 2018;13(1):61.

171. Braendengen M, Hansson K, Radu C, Siegbahn A, Jacobsson H, Glimelius B. Delineation of gross tumor volume (GTV) for radiation treatment planning of locally advanced rectal cancer using information from MRI or FDG-PET/ CT: a prospective study. Int J Radiat Oncol Biol Phys. 2011;81(4):e439-45.

172. Buijsen J, van den Bogaard J, Janssen MH, Bakers FC, Engelsman S, Ollers M, et al. FDG-PET provides the best correlation with the tumor specimen compared to MRI and CT in rectal cancer. Radiother Oncol. 2011;98(2):2706.

173. Deantonio L, Caroli A, Puta E, Ferrante D, Apicella F, Turri L, et al. Does baseline [18F] FDG-PET/CT correlate with tumor staging, response after neoadjuvant chemoradiotherapy, and prognosis in patients with rectal cancer? Radiat Oncol. 2018;13(1):211.

174. Habr-Gama A, Perez RO, Nadalin W, Sabbaga J, Ribeiro U Jr, Sousa AH SE Jr, et al. Operative versus nonoperative treatment for stage 0 distal rectal cancer following chemoradiation therapy: long-term results. Ann Surg. 2004; 240(4):711-7 discussion 7-8.

175. Bang JI, Ha S, Kang SB, Lee KW, Lee HS, Kim JS, et al. Prediction of neoadjuvant radiation chemotherapy response and survival using pretreatment [(18)F]FDG PET/CT scans in locally advanced rectal cancer. Eur J Nucl Med Mol Imaging. 2016;43(3):422-31.

176. Lovinfosse P, Polus M, Van Daele D, Martinive P, Daenen F, Hatt M, et al. FDG PET/CT radiomics for predicting the outcome of locally advanced rectal cancer. Eur J Nucl Med Mol Imaging. 2018;45(3):365-75.

177. Maffione AM, Marzola MC, Capirci C, Colletti PM, Rubello D. Value of (18)FFDG PET for predicting response to Neoadjuvant therapy in rectal Cancer: systematic review and meta-analysis. AJR Am J Roentgenol. 2015;204(6): $1261-8$.

178. Rymer B, Curtis NJ, Siddiqui MR, Chand M. FDG PET/CT can assess the response of locally advanced rectal Cancer to Neoadjuvant Chemoradiotherapy: evidence from meta-analysis and systematic review. Clin Nucl Med. 2016;41(5):371-5.

179. Flam M, John M, Pajak TF, Petrelli N, Myerson R, Doggett S, et al. Role of mitomycin in combination with fluorouracil and radiotherapy, and of salvage chemoradiation in the definitive nonsurgical treatment of epidermoid carcinoma of the anal canal: results of a phase III randomized intergroup study. J Clin Oncol. 1996;14(9):2527-39.

180. Day FL, Link E, Ngan S, Leong T, Moodie K, Lynch C, et al. FDG-PET metabolic response predicts outcomes in anal cancer managed with chemoradiotherapy. Br J Cancer. 2011;105(4):498-504.

181. Glynne-Jones R, Nilsson PJ, Aschele C, Goh V, Peiffert D, Cervantes A, et al. Anal cancer: ESMO-ESSO-ESTRO Clinical Practice Guidelines for diagnosis, treatment and follow-up. Ann Oncol. 2014;25(Suppl 3):iii10-20.

182. Jones M, Hruby G, Solomon M, Rutherford N, Martin J. The role of FDG-PET in the initial staging and response assessment of anal Cancer: a systematic review and meta-analysis. Ann Surg Oncol. 2015;22(11):3574-81.

183. Albertsson P, Alverbratt C, Liljegren A, Bjorkander E, Strandell A, Samuelsson $\mathrm{O}$, et al. Positron emission tomography and computed tomographic (PET/ $\mathrm{CT}$ ) imaging for radiation therapy planning in anal cancer: a systematic review and meta-analysis. Crit Rev Oncol Hematol. 2018;126:6-12.

184. Dapper H, Schiller K, Munch S, Peeken JC, Borm K, Weber W, et al. Have we achieved adequate recommendations for target volume definitions in anal cancer? A PET imaging based patterns of failure analysis in the context of established contouring guidelines. BMC Cancer. 2019;19(1):742

185. Krengli M, Milia ME, Turri L, Mones E, Bassi MC, Cannillo B, et al. FDG-PET/CT imaging for staging and target volume delineation in conformal radiotherapy of anal carcinoma. Radiat Oncol. 2010;5:10.

186. Sabbagh A, Jacobs C, Cooke R, Chu KY, Ng SM, Strauss WY, et al. Is there a role for an 18F-fluorodeoxyglucose-derived biological boost in squamous cell anal Cancer? Clin Oncol (R Coll Radiol). 2019;31(2):72-80.

187. Jones MP, Hruby G, Metser U, Sridharan S, Capp A, Kumar M, et al. FDG-PET parameters predict for recurrence in anal cancer - results from a prospective, multicentre clinical trial. Radiat Oncol. 2019;14(1):140.

188. Nguyen BT, Joon DL, Khoo V, Quong G, Chao M, Wada M, et al. Assessing the impact of FDG-PET in the management of anal cancer. Radiother Oncol. 2008;87(3):376-82.

189. Schwarz JK, Siegel BA, Dehdashti F, Myerson RJ, Fleshman JW, Grigsby PW. Tumor response and survival predicted by post-therapy FDG-PET/CT in anal cancer. Int J Radiat Oncol Biol Phys. 2008;71(1):180-6.

190. Houard C, Pinaquy JB, Mesguich C, Henriques de Figueiredo B, Cazeau AL, Allard JB, et al. Role of (18)F-FDG PET/CT in Posttreatment evaluation of anal carcinoma. J Nucl Med. 2017;58(9):1414-20.

\section{Publisher's Note}

Springer Nature remains neutral with regard to jurisdictional claims in published maps and institutional affiliations.

\section{Ready to submit your research? Choose BMC and benefit from:}

- fast, convenient online submission

- thorough peer review by experienced researchers in your field

- rapid publication on acceptance

- support for research data, including large and complex data types

- gold Open Access which fosters wider collaboration and increased citations

- maximum visibility for your research: over $100 \mathrm{M}$ website views per year

At BMC, research is always in progress.

Learn more biomedcentral.com/submissions 